\title{
The use of prosody during syntactic processing in children and adolescents with autism spectrum disorders
}

\section{Citation}

Diehl, Joshua John, Carlyn Friedberg, Rhea Paul, and Jesse Snedeker. 2014. “The Use of Prosody During Syntactic Processing in Children and Adolescents with Autism Spectrum Disorders." Development and Psychopathology 27 (03) (August 26): 867-884. doi:10.1017/ s0954579414000741.

\section{Published Version}

10.1017/s0954579414000741

\section{Permanent link}

http://nrs.harvard.edu/urn-3:HUL.InstRepos:32094210

\section{Terms of Use}

This article was downloaded from Harvard University's DASH repository, and is made available under the terms and conditions applicable to Open Access Policy Articles, as set forth at http:// nrs.harvard.edu/urn-3:HUL.InstRepos:dash.current.terms-of-use\#OAP

\section{Share Your Story}

The Harvard community has made this article openly available.

Please share how this access benefits you. Submit a story. 
The Use of Prosody During Syntactic Processing in Children and Adolescents With Autism Spectrum Disorders

\author{
Joshua John Diehl ${ }^{1}$ \\ Carlyn Friedberg ${ }^{2}$ \\ Rhea Paul ${ }^{3}$ \\ Jesse Snedeker ${ }^{2}$
}

${ }^{1}$ Center for Children and Families, Dept. of Psychology, University of Notre Dame, IN

${ }^{2}$ Department of Psychology, Harvard University, Cambridge, MA

${ }^{3}$ Yale Child Study Center, Yale University School of Medicine, New Haven, CT

Acknowledgements. We would like to thank the children and families who made this work possible. We are grateful to Heidi Miller, the Sonya Ansari Center for Autism at Logan (South Bend, IN), Lauren Berkovits, Daria Diakonova, Amanda Worek, Debra Loprete, Theresa Gorman, Michelle Won, Terri Sweeney, and Karen Tang for their contributions to this project, which included participant recruitment, data collection, manuscript review and data management. This paper was supported in part by the NIDCD Grant \# K24 HD045576 awarded to Rhea Paul, and NICHD Grant \# P01-HD03008 (Project 3).

Correspondence concerning this article should be addressed to: Joshua John Diehl, Ph.D. Department of Psychology, 118 Haggar Hall, University of Notre Dame, Notre Dame, IN 46556. Phone: (574) 631-1371. Fax: (574) 631-8883. Email: joshua.diehl@ nd.edu. 


\begin{abstract}
In this study, we employed an eye-gaze paradigm to explore whether children (8-12) and adolescents (12-18) with autism spectrum disorders (ASD) are able to use prosodic cues to determine the syntactic structure of an utterance. Persons with ASD were compared to typicallydeveloping (TD) peers matched on age, IQ, gender, and receptive language abilities. The stimuli were syntactically ambiguous but had a prosodic break that indicated the appropriate interpretation (feel the frog... with the feather vs. feel...the frog with the feather). We found that all groups were equally sensitive to the initial prosodic cues that were presented. Children and teens with ASD used prosody to interpret the ambiguous phrase as rapidly and efficiently as their TD peers. However, when a different cue was presented in subsequent trials, the younger ASD group was more likely to respond in a manner consistent with the initial prosodic cue rather than the new one. Eye-tracking data indicated that both younger groups (ASD and TD) had trouble shifting their interpretation as the prosodic cue changed, but the younger TD group was able to overcome this interference and produce an action consistent with the prosodic cue.
\end{abstract}

KEYWORDS: Autism, prosody, intonation, syntax, communication 


\section{The Use of Prosody During Syntactic Processing in Children With Autism Spectrum}

\section{Disorders}

Autism Spectrum Disorders (ASD) are neurodevelopmental disorders characterized by deficits in social interaction and communication, along with a propensity to engage in repetitive behaviors or have restricted interests (APA, 2000). The severity of these deficits and the ways in which they are expressed vary considerably. Until recently, most children diagnosed with ASD had severe language impairments or delays, and researchers estimated that as many as half were non-verbal (Lord \& Paul, 1997). However, more recent estimates suggest that $80-86 \%$ of children with ASDs have some functional language (Lord, Risi, \& Pickles, 2004). In fact, a substantial proportion of the school-aged children with ASD do not appear to have deficits in vocabulary, articulation or syntax (Joseph, Tager-Flusberg \& Lord, 2002; Kjelgaard \& TagerFlusberg, 2001. We will be referring to children with this profile as highly verbal.

There are, however, two domains of language that appear to be impaired even in highlyverbal children with ASD. First, persons with ASD have impairments in pragmatics (Kelley, Paul, Fein \& Naigles, 2006; Tager-Flusberg, Paul, \& Lord, 2005; Young, Diehl, Morris, Hyman, \& Bennetto, 2005), that seem related to their deficits in social interaction. Pragmatics represents the skills that allow us to use language as a social tool by going beyond the literal meaning of an utterance to understand the role that it plays in a particular interaction. Highly-verbal persons with ASD often perform well on highly structured measures of pragmatic ability (Young et al., 2005). Nonetheless, children with this profile have been found to have deficits in: interpreting the conversational intentions (and sometimes the meaning) of non-literal speech acts (Adachi et al., 2004; Martin \& McDonald, 2004; MacKay \& Shaw, 2004); determining the amount or kind of information to provide in a conversation (Ghaziuddin \& Gerstein, 1996; Paul, Orlovski, 
Marchinko, \& Volkmar, 2009); producing pragmatically appropriate responses during a conversation (Adams, Green, Gilchrist \& Cox, 2002); and inferring information that is missing from the discourse (Le Sourn-Bissaoui, Caillies, Gierski \& Motte, 2009; Loukusa et al., 2007).

Second, the use of prosody is often atypical in ASD, even in persons with no structural language impairments (see Tager-Flusberg, et al., 2005 for review). The term prosody refers to the suprasegmental characteristics of speech including pitch, duration and intensity. Descriptions of prosody in ASD have varied from flat and monotonous to variable, sing-song, or pedantic (e.g., Kanner, 1943; Lord \& Paul, 1997; Provonost, Wakstein, \& Wakstein, 1966). Atypical prosodic production has been documented at all levels of ability within the autism spectrum (e.g., Baltaxe, 1984; Diehl \& Paul, 2012; Diehl \& Paul, in press; Grossman, Bemis, Plesa Skwerer, \& Tager-Flusberg, 2010; Nadig \& Shaw, 2012; Paul, Augustyn, Klin, \& Volkmar, 2005; Peppé, McCann, Gibbon, O'Hare, \& Rutherford, 2007; Shriberg, Paul, Black, \& van Santen, 2011). There is a smaller but growing body of research exploring whether people with ASD also have deficits in the use of prosody during language comprehension (see next section for a brief review). Much of this work has focused on prosodic cues to a speaker's emotional state and pragmatic intentions, but prosody also plays a role in lexical segmentation, lexical identification, and syntactic parsing. Research on these non-pragmatic functions of prosody in ASD is critical for determining whether there are prosodic deficits that are separate from the general pragmatic deficit noted earlier. Although work in this area has begun, the findings so far leave many questions unanswered (Chevallier, Noveck, Happe \& Wilson, 2009; Diehl, Bennetto, Watson, Gunlogson, \& McDonough, 2008; Grossman et al., 2010; Paul et al., 2005; Peppe et al., 2007). The present study explores how children and adolescents with ASD use prosodic cues to disambiguate the syntactic structure of an utterance. It also addresses 
unanswered questions about how this ability develops in typical children between the ages of 7 and 17. In our paradigm, participants hear instructions with syntactic ambiguities which are resolved by the placement of prosodic boundaries, while their eye-movements are recorded. This design allows us to measure how prosody influences comprehension over time. In the remainder of the introduction, we discuss: the prior evidence for deficits in the perception and comprehension of prosody in ASD, with a focus on syntactic parsing; recent work on prosody and syntactic parsing in typically-developing preschoolers; and the hypotheses that motivate the present experiment.

\section{The Perception and Comprehension of Prosody in ASD}

Prosody is a structure which organizes the phonetic form of an utterance into larger units (e.g., prosodic words and intonational phrases) and assigns prominence to units within this structure (Selkirk, 1986; Beckman, 1996; Shattuck-Hufnagel \& Turk, 1996). This prosodic structure is marked by changes in the acoustic properties of speech such as fundamental frequency, duration, pausing, and intensity. The prosodic form that a speaker uses for an utterance is shaped by its lexical content, its syntactic structure, the role of the utterance in the discourse, the speaker's emotional state and speech rate, and the intended audience (ShattuckHufnagel \& Turk, 1996; Wagner \& Watson, 2010 for reviews). Thus prosodic form contains valid cues to the syntactic, semantic, and pragmatic interpretation of an utterance. These cues are rapidly exploited by listeners during language comprehension (Ito \& Speer, 2008; Snedeker \& Trueswell, 2003; see Wagner \& Watson, 2010 for review).

Much of the research on the comprehension of prosody in ASD has focused on information at the pragmatic level. For example, several studies have found that even highfunctioning persons with ASD have deficits in using vocal cues to identify the speaker's emotion 
(Chevallier et al., 2011; Golan, et al., 2007; Järvinen-Pasley, Peppé, King-Smith, \& Heaton, 2008a; Kleinman, Marciano, \& Ault, 2001; Peppé et al., 2007; Rutherford, Baron-Cohen, \& Wheelwright, 2002) and using contrastive stress as a cue to discourse structure (Paul et al., 2005; Nappa \& Snedeker, 2012), despite fairly strong general language abilities. However, there are good reasons for suspecting that the prosodic comprehension deficit in ASD extends beyond the use of prosody as a pragmatic cue. Electrophysiological studies suggest that the processing of the acoustic correlates of prosodic structure (such as frequency and intensity) is atypical in ASD (Kujala et al., 2007; Kujala et al., 2010; Lepistö, Silokallio, Nieminen-von Wendt, Alku, Näätänen, \& Kujala, 2006; Russo et al., 2008). Because the perception of pitch is critical for determining the prosodic structure of an utterance, a deficit of this kind would be expected to interfere with both the pragmatic and non-pragmatic functions of prosody.

Thus, it is somewhat surprising that the existing studies on prosodic comprehension provide only weak evidence for deficits in non-pragmatic tasks. The three studies which have explored the use of prosodic stress for lexical identification (e.g., reCORD vs REcord) have found no differences between persons with ASD and well-matched controls (Chevallier et al, 2009; Grossman et al., 2010; Paul et al., 2005), though there is a consistent decrement in performance across the three studies (3-6\%) which fails to reach significance.

In addition, the role of prosody in syntactic parsing has been explored in five experiments, with a mixed pattern of findings. Four of these experiments used judgment tasks, in which participants heard an utterance with a grouping ambiguity (e.g., chocolate biscuits and jam vs. chocolate, biscuits and jam) and then selected a picture or gloss that matched the utterance or judged whether a picture matched the utterance. Three of these studies found no difference between persons with ASD and typically-developing controls (Chevallier et al., 2009; 
Paul et al., 2005; Peppé, McCann, Gibbon, O’Hare, \& Rutherford, 2007), while one found that persons with ASD performed reliably worse than age and language matched controls (JärvinenPasley et al., 2008a). Although these differences are open to many interpretations, age and developmental level may play a role. The participants in the Järvinen-Pasley study were younger $(\mathrm{M}=12 ; 7)$ and less verbally proficient than those in the Paul and Chevallier studies, suggesting that deficits in the use of prosody for syntax may resolve over development. In contrast, the children in the Peppé study were even younger $(M=9 ; 10)$, however the performance of the control group was quite low suggesting that the task may have been too difficult for these younger language-matched children $(\mathrm{M}=6 ; 10)$.

This explanation, however, cannot readily account for the fifth study. Diehl and colleagues (Diehl, Bennetto, Watson, Gunlogson, \& McDonough, 2008) compared the prosodic comprehension in adolescents with high-functioning ASD to a control group matched on age, IQ, and receptive language abilities. Participants heard syntactically ambiguous sentences, like (1) and (2), in which prosody could be used to determine the correct action.

1. Put the dog...in the box on the star (Put the dog into the box that's on a star).

2. Put the dog in the box... on the star (Put a dog that's in a box onto a star).

The group with ASD was less likely than their typically developing peers to act in concordance with the prosodic cue. Diehl's participants were similar in age, IQ and language level to those in the Chevallier and Paul studies. Thus, any difference in performance presumably reflects the differences in the tasks that were used. One possibility is that the overt judgment tasks used by Chevallier and Paul may have drawn participants' attention to the ambiguity and the contrasting prosodies, allowing them to adopt an explicit strategy incorporating these cues (Klin, Jones, Schultz \& Volkmar, 2003; Paul et al., 2005). In contrast, the participants in the Diehl task may 
have followed the commands without becoming aware of the ambiguity. If this were true, we would expect ASD participants to be slower in making the overt judgments than controls, who presumably do not need to devise task-specific strategies. However, Chevallier found no difference in reaction times between the groups.

A second possibility is that the ASD group had difficulties with the Diehl task that were unrelated to prosody. Diehl and colleagues used ambiguous sentences with the verb put, which requires two post-verbal arguments: an object to be moved and a location to which it should be moved. This creates a strong bias to initially interpret the first prepositional phrase (in the box) as a destination, resulting in verb-phrase attachment (Tanenhaus, Spivey-Knowlton, Eberhard, \& Sedivy, 1995). Critically, in the Diehl study, the ASD group only had difficulty with stimuli in which the prosodic cue was in conflict with this initial lexical bias. In typical adults, this initial bias can be revised if subsequent information indicates that this interpretation is incorrect (e.g., the prosodic break followed by a second prepositional phrase), but young children fail to revise these initial commitments (Trueswell, Sekerina, Hill, \& Logrip, 1999). This ability to revise emerges gradually between five and eleven years of age (Weighall, 2008). Therefore, it is possible that the performance of the ASD group in the Diehl study is not the result of a deficit in the use of prosody, but instead reflects a deficit in the ability to revise misinterpreted sentences.

\section{The Use of Prosody for Syntactic Analysis in Typically Developing Children}

Curiously, when younger typically-developing children (3-7 years) are tested on prosodic parsing using choice tasks like those above, they also perform quite poorly (Choi \& Mazuka, 2003; Mazuka, Jincho \& Oishi, 2009). These failures are unlikely to result from a basic deficit in prosodic perception. Prosody plays a central role in early speech perception: newborns prefer languages that are prosodically similar to their own (Mehler, Jusczyk, Lambertz, Halsted, 
Bertoncini, \& Amiel-Tison, 1988), older infants use prosodic structure to find words in the speech stream (Johnson \& Jusczyk, 2001) and prosodic information may even be used during the acquisition of syntax (Christophe, Millotte, Bernal \& Lidz, 2008; Morgan, 1996).

Snedeker and Yuan (2008) suggested that young children's failure in prosody for parsing tasks was due to the design of these experiments (see also Mazuka et al., 2009). Specifically, like the ASD studies, these experiments used within-subject designs which required children to shift between two response types across trials. Thus, to succeed in these tasks, children must override the interpretation that they got on the last trial to arrive at the correct interpretation on the next. Snedeker \& Yuan (2008) tested this hypothesis using a blocked design. In the first half of the study, prosodic form was manipulated between participants: half the children received instructions like (3) and half received ones like (4).

3. You can pinch the bear..... with the barrette. (Use the barrette to pinch)

4. You can pinch.....the bear with the barrette. (Pinch the one that has a barrette)

Then, in the second half, the conditions flipped, and participants were given new sentences with the other prosody. These sentences contain only a single ambiguous prepositional phrase (in contrast with the Diehl study), thus there is no need for participants to revise their analysis of this phrase based on subsequent words. Four and five-year-old children carried out the instructions as accurately as adults in the first half, indicating that they were sensitive to these prosodic cues and able to use them for syntactic parsing. However, in the second half the children tended to perseverate resulting in chance level performance.

Snedeker \& Yuan (2008) used an additional measure: as participants listened to the instructions their eye movements were recorded, providing information about how their interpretation of the utterance changed over time (Tanenhaus et al., 1995). They found that, 
during the first block, children began using prosodic information about 500 milliseconds after the onset of the critical word ("barrette" in $3 \& 4$ ), just a few hundred milliseconds after the adults. Thus they concluded that young children rapidly and spontaneously use prosodic information to resolve syntactic ambiguities, but these abilities can be masked by perseveration across trials in within-subject designs.

\section{The Goals of this Study}

In the present study, we use the Snedeker \& Yuan (2008) task to explore prosodic comprehension in children and adolescents with high-functioning ASD and in typicallydeveloping (TD) peers matched for age, language ability and IQ. This will allow us to address four open questions. First, are highly-verbal children and adolescents with ASD less likely to use prosodic information during syntactic parsing than TD children? As noted above, the findings of the prior experiments are mixed and their interpretation is uncertain. If there is a prosodic comprehension deficit in ASD, which disappears in explicit judgment tasks that focus attention on prosodic cues, then this deficit should be visible in the open-ended act out task, particularly in the first block when participants have heard only one form of the utterance. However, if the differences between groups in the previous studies are due solely to difficulties with syntactic revision or perseveration, then the ASD group should perform as well as TD peers in the first block where there is no need to revise or resist prior interpretations.

Second, do children and adolescents with ASD make use of prosodic cues to syntax as rapidly as TD peers do? If prosodic comprehension in ASD is the result of slow strategic processes, then prosody should have little or no influence on the early eye-movements of this group. In contrast, if individuals with ASD are processing this information in the same way as same-age peers, then the effects of prosody should emerge at the same time for both groups. 
Third, how does this profile of abilities change from middle childhood into adolescence? To date there is no research on how online use of prosody develops in TD children after the age of six. The prior studies using explicit judgment tasks tentatively suggest that performance in typical children improves rapidly around six to nine years of age (Vogel \& Raimy, 2002), but this improvement may be delayed by a few years in children with ASD, resulting in group differences during the later part of middle childhood (Järvinen-Pasley et al., 2008a) which resolve by adolescence (Chevallier et al., 2009; Paul et al., 2005). To test this developmental hypothesis we tested two age groups: children (8-12 years) and adolescents (13-18 years).

Fourth, how are prosodic comprehension abilities in both populations affected by interference from prior utterances? We know that typical adults flexibly shift between interpretations in this task, and preschoolers do not, but we do not know when typical children gain this ability. If it emerges at the same time as the ability to revise garden path sentences, then we should expect substantial changes between five and eleven. If the ability to resist interference is impaired in ASD, then performance on the second block of trials should be worse than performance on the first.

\section{Methods}

\section{Participants}

Autism spectrum disorders group. Participants in this group were 48 individuals with high-functioning ASD who were between 7 and 17 years and had verbal abilities within (or above) the normal range (see Table 1). Participants were recruited from databases at the University of Notre Dame, Harvard University, and the Yale Child Study Center; thus approximately half of our sample was living in the Midwest and half in the Northeast. During an initial phone screening, parents were asked about the results of previously administered 
standardized tests to facilitate group matching. Families were invited to participate if this interview suggested that they would meet the inclusion criteria (see below).

Each participant was independently evaluated by our research team for diagnostic confirmation, and met DSM-IV-TR (APA, 2000) criteria for one of the three ASD diagnoses (Autistic Disorder, Asperger's Disorder, or Pervasive Developmental Disorder, Not Otherwise Specified). Diagnostic confirmation was based on administration of the Autism Diagnostic Observation Schedule-Generic (Lord et al., 2000), the Autism Diagnostic Interview-Revised (Rutter, Le Couteur, \& Lord, 2003) or the Social Communication Questionnaire - Lifetime Form (SCQ-L; Rutter, Bailey, Berument, Lord, \& Pickles, 2003), as well as the judgment of the experienced clinicians on the research team (which included a clinical psychologist with considerable experience in ASD diagnosis and a licensed speech-language pathologist). IQ was measured using either the Wechsler Abbreviated Scale of Intelligence (Wechsler, 1999) or the Differential Ability Scales (Elliott, 1990). Participants also completed the subtests in the Clinical Evaluation of Language Fundamentals - Fourth Edition (CELF-4; Semel, Wiig, \& Secord, 2003) necessary for a Receptive Language Index (RLI) score. Participants were excluded from this study: if they had a Full Scale IQ (FSIQ), Verbal IQ (VIQ), or CELF-4 RLI score below 80; if English was not their first language and the primary language spoken at home; or if they had any uncorrected vision or hearing deficits that would have interfered with study administration. Twenty-one participants were recruited for our ASD group but were not included in our final sample of 48 participants (eight did not meet diagnostic criteria, 12 had IQ or language scores below 80, and one was dropped because of technical issues with session video). Our ASD sample was 96\% Caucasian and 4\% Other. We did not collect data on the socio-economic status of our participants. 
Typically developing comparison group. Participants included a sample of 48 individuals between the ages of 7 and 17 (see Table 1). TD participants were recruited from databases at the University of Notre Dame, Harvard University, and the Yale Child Study Center. All participants in this group had no first degree relatives with an ASD, no previous history of clinical diagnosis or special educational services, and were reported to be in the appropriate grade for their age in school. Participants were screened for an ASD diagnosis using the SCQ-L and the clinical judgment of the research team described above. All had FSIQ, VIQ, and CELF-4 RLI standard scores above 80. Eight participants were recruited for our comparison group but were excluded from the final sample of 48 (three for technical problems, three for failure to complete the study, and two were removed before data analysis to facilitate group matching). Our comparison group was 92\% Caucasian, 4\% African-American, and 4\% Other.

Groups and Matching. Participants in each group were divided into two groups based on an age cutoff (12.5 years), creating four groups: (a) participants with ASD younger than the cutoff (ASD child), (b) participants with ASD older than the cutoff (ASD teen), (c) TD peers below the cutoff (TD child), and (d) TD peers above the cutoff (TD teen). The child groups had an average age and developmental level that was between that of the participants in the Peppé (2007) and Järvinen-Pasley (2008a) studies, while the teen groups were similar in age to the participants in the Chevallier (2009) and Paul (2005) studies. The TD and ASD participants in each age group were matched on chronological age and all four groups were matched on gender, FSIQ, VIQ, and CELF-4 Receptive Language Index (Table 1).

\section{Procedure}

Participants were tested individually in a quiet room in our laboratories or in the participant's home. The procedure for the experimental task was modeled closely on Snedeker 
\& Yuan (2008). Participants were told that they would be playing a game about following instructions. They were seated in front of an inclined podium with props (see Figure 1) and a camera in the middle which was focused on the participant's face allowing us to code eye fixations after the experiment was completed. A second camera, placed behind the participant and to the side, recorded their actions. At the beginning of each trial, the experimenter laid out the props and labeled each one twice. Then s/he played prerecorded sound files through external computer speakers. On each trial, the child heard an instruction to look at a fixation point at the center of a display, followed by a command to act on the toys. After completing this action, the child heard a second command and completed it, before moving on to the next trial. The experimenter moved out of the child's view before the first sentence and remained there until the action was completed.

\section{Stimuli}

The sound files and the toy sets that were used in the present study were the same as those used in Snedeker \& Yuan (2008) and are described in greater detail in that paper. On the critical trials, the commands were syntactically ambiguous as in (5).

5. You can feel the frog with the feather.

Specifically, each critical instruction contained a prepositional phrase headed by with that could be syntactically parsed as a part of the noun phrase (NP-attachment) or as a part of the verb phrase (VP-attachment). NP-attachment results in the phrase being semantically interpreted as a modifier (the frog that has the feather) while VP-attachment results in it being interpreted as an instrument (use the feather to feel the frog). These sentences were constructed to ensure that the verb and prepositional object were not biased toward either a modifier or instrument reading (see Snedeker \& Trueswell, 2004). 
Prosody was manipulated by placing an intonational phrase break before the first noun phrase (You can feel...the frog with the feather) to indicate a modifier reading or before the prepositional phrase (You can feel the frog ... with the feather) to indicate an instrument reading. This manipulation of prosody was based on the production patterns observed in child-directed speech (Snedeker \& Yuan, 2008) and adult-directed speech (Snedeker \& Trueswell, 2003). The set of toys that accompanied each critical trial consisted of: (a) a target instrument, a full scale object which could be used to carry out the action (e.g., a feather), (b) a target animal, a stuffed animal holding a small replica of the target instrument (e.g., a frog with a feather), (c) a distractor instrument, and (d) a distractor animal holding a small replica of the distractor instrument (see Figure 1). The placement of the toys on the shelves was counterbalanced across trials such that each type of toy (e.g., target instrument) appeared in each quadrant.

We would expect participants who heard instrument prosody to arrive at a syntactic analysis where the prepositional phrase was VP-attached and semantically interpreted as an instrument. This should result in more looks to the target instrument after the onset of the critical word ("feather") and use of the target instrument to act upon the target animal. In contrast, participants who heard modifier prosody should interpret the prepositional phrase as an NPattached modifier indicating (redundantly) the animal that they should act upon. This should result in few looks to the target instrument and actions upon the target animal without the use of any instrument. Prior studies have documented this pattern in both adults and preschool-aged children (Snedeker \& Trueswell, 2003; Snedeker \& Trueswell, 2004; Snedeker \& Yuan, 2008).

\section{Design}

We used a blocked design: Prosody was manipulated within participant but the instrument and modifier prosody trials were not intermixed. Instead participants were given all 
the trials of one prosody type before hearing any trials of the other type. Prosody was counterbalanced across lists such that every sentence occurred with both modifier and instrument prosody across participants and each participant heard just one version of each sentence. Trial order was also counterbalanced. As a result, half the participants in every group heard the instrument prosody first and half heard the modifier prosody first. The critical trials were interspersed with filler trials using instructions that were globally unambiguous. The experiment began with two practice trials, followed by 19 trials ( 8 critical trials and 11 unambiguous fillers). Each trial included two commands. On the critical trials, the first command was always the critical command, and the second instruction was an unambiguous filler. Thus, participants heard a total of 38 commands (not including practice trials), eight of which were critical ambiguous commands.

\section{Coding}

Trained coders, who were naive to group membership and study goals, watched the videos from the action camera and classified actions into one of four categories: (a) instrument responses (i.e., the target instrument was used to execute the act on the target animal), (b) miniinstrument responses (i.e., the participant used the small version of the instrument that was attached to the target animal to execute the action), (c) modifier responses (i.e., the participant executed the action on the target animal themselves, without the instrument), and (d) other responses (i.e., the participant performed a different action than was specified in the command, or acted on one of the distractor objects). Mini-instrument responses were treated as instrument responses in the data analysis, following Snedeker \& Yuan (2008). Reliability between coders, performed on $20 \%$ of the participants, was very high $(k=.96$, range $=.77-1.00)$, and disagreements were resolved by consensus. 
Eye movements were coded from the videotape of the participant's face, using frame-byframe viewing. The video was recorded at the standard 30 frames per second. One coder, who had the audio on, recorded the time at which the critical sentence began and the time at which the action began. A second coder was provided with this information and coded the onset of each change in gaze and the direction of each subsequent fixation during this time window, with the audio off. This coder was blind to the prosodic form of the utterance and to the location of each toy (because the toys were not visible in video). The participant's direction of fixation was coded as being to one of the four quadrants of the podium, to the center hole (at the camera), or away from the display. Any frames in which the participants' eyes were not visible were excluded from the analyses. Blinks without a fixation change were coded as being to quadrant of the fixation, blinks with a fixation change during the blink were coded as being to the quadrant of the subsequent fixation (like all other saccades). Twenty-three percent of participants were coded by an additional coder, who achieved high reliability on direction of gaze $(k=.84$, range .64 - 1). Disagreements were resolved by a third person. This method of collecting and coding eye-movements has been used extensively and validated against an automated eye-tracking system (see Snedeker \& Trueswell, 2004).

We coded and analyzed the eye-movements for all trials, including those where the participant did not give the predicted response (e.g., a modifier action for a sentence with instrument prosody). In reaction time studies, alternative responses are generally considered errors, and are usually excluded from the analysis. In contrast, in visual-world studies using an act-out task, alternative responses are typically included in the eye-gaze analyses for a number of reasons. First, these responses also presumably reflect linguistic processing (since the correct action and animal are used), rather than simple guesses. Second, the goal of an eye-tracking 
study is to determine how the interpretation of an utterance unfolds over time, independent of the ultimate response. Third and most critically, removing data based on the participant's response could result in false findings since where a participant is looking at one time can shape their subsequent interpretation of an ambiguous phrase (e.g., Trueswell et al., 1999).

\section{Results}

The results are divided into two sections below. First, we analyze the participants' actions to understand their final interpretation of the ambiguous utterance. Second, we analyze the participants' fixations as the utterance unfolds over time to explore the process of momentto-moment language comprehension. Because of the prior evidence for perseveration in this task in younger children, we analyzed each block of trials separately.

Our primary analyses were mixed-effects logistic regressions which included fixed effects for: Prosody (modifier or instrument), Age (child or teen), Diagnosis (TD or ASD) and all interactions of these variables. An effects-coding scheme was used with first listed level of each variable coded as -1 and the second as 1 . Thus the main effects in these analyses can be interpreted as if they were ANOVA's. ${ }^{1}$ Whenever we found an interaction between one of the participant variables (Age or Diagnosis) and Prosody, we split the sample on that participant variable and conducted separate analyses of the two groups to understand the nature of the effect. In addition, we conducted separate analyses of the four populations (ASD-Child, TD-Child, ASD-Teen, and TD-Teen) to determine which effects were reliably present in an individual group. All analyses included random effects for both Subject and Verb. ${ }^{2}$

\footnotetext{
${ }^{1}$ We also conducted ANOVA's by subject. These analyses produced a similar pattern of effects, though some of the critical interactions in Block 2 were marginal.

${ }^{2}$ In all cases, parallel analyses were run with the maximally-appropriate random-effects structure (random slopes and interactions for each verb). We compared these models--whether they converged or not--with the models that just contained just random intercepts using a chi-squared test. For the primary, omnibus, analyses the more complex models consistently failed to converge and did not appear to provide a reliably better fit for the data. In the other
} 


\section{Actions}

Figure 2 plots the proportion of trials in the first block on which participants performed instrument actions, thus revealing that they had interpreted the ambiguous prepositional phrase as VP-attached. Figure 3 plots the proportion of instrument actions during the second block of trials. Table 2 lists the results of the mixed models for both Blocks.

On Block 1, all four groups were strongly influenced by prosody and used it to roughly the same degree, resulting in a robust effect of Prosody, no effect of Age or Diagnosis, and no interactions between these variables and Prosody. Separate models for each of the four groups of participants (child TD, child ASD, teen ASD, teen TD) confirmed that the effect of Prosody was reliable in all of them (see Table 5 for statistics).

The pattern in Block 2 was different. Again there was a reliable main effect of Prosody in the omnibus ANOVA. However, there were also reliable interactions between Prosody and Age and between Prosody and Diagnosis, indicating that the effect of our manipulation varied across participant groups. To follow up on the interaction of Prosody and Age, we analyzed the teens and the children separately. In the teens, we found the expected effect of Prosody $(z=$ 4.98, $p<.001, \beta=2.11)$ but no main effect of or interaction with Diagnosis $(|z|$ 's $<1, p$ 's $>.5,|\beta|$ $<.25)$. Thus, teenagers with ASD performed as well as typically developing teens. In contrast, in the children, there was both a main effect of Prosody $(z=3.21, p=.001, \beta=3.21)$ and a robust interaction of Diagnosis and Prosody $(z=-2.88, p=.004, \beta=-.79)$, indicating that the children with ASD performed worse than their typically developing peers.

To follow up on the interaction between Prosody and Diagnosis we analyzed the typically developing children and the children with ASD separately. These analyses confirmed the pattern 
described above. In the typical group, we found a robust effect of Prosody $(z=5.78, p<.0001$, $\beta=1.72)$ and no effect of or interaction with Age $\left(z^{\prime} s<1, p^{\prime} s>.3,|\beta|<.25\right)$. However in the ASD group the effect of Prosody $(z=2.77, p=.006, \beta=.98)$ was superseded by an interaction of Age and Prosody $(z=2.42, p=.02, \beta=.82)$.

Critically, when we constructed separate models for each of the four groups we found that both groups of teens and the TD child group showed a reliable effect of Prosody on their actions, while the ASD child group did not (see Table 6 for statistics). Thus although all participants were able to use prosody to guide their final interpretation of the utterances in the first block of trials, those in the ASD child group were at chance in the second block, suggesting that they had difficulty shifting their interpretation of the ambiguous utterance when the prosodic cues changed.

To get an approximate measure of reaction times, we calculated the number of frames from the onset of the prepositional object to the onset of the action. The reaction times for each Block were analyzed using a mixed-model linear regression with the same independent variables as the action analyses. We found no effects of Age or Diagnosis and no interactions with these variables $\left(|z|\right.$ 's $<1.7, p^{\prime} \mathrm{s}>.1,|\beta|$ 's $\left.<3\right)$. In Block 1, participants responded more slowly to instrument prosody than to modifier prosody $(M=1561 \mathrm{~ms}$ for instrument and $\mathrm{M}=1325 \mathrm{~ms}$ for modifier, $\mathrm{z}=2.55, p=.01, \beta=3.18)$. In Block 2 , they responded more quickly to instrument prosody than modifier prosody $(\mathrm{M}=1176 \mathrm{~ms}$ for instrument and $\mathrm{M}=1455 \mathrm{~ms}$ for modifier, $z=-$ $3.29, p=.001, \beta=-4.28)$.

\section{Temporal Analysis of Eye Movements}

To explore how participants' interpretation of the utterance changed over time, we examined fixations to the target instrument for both Block 1 (Figures 4a \& b) and Block 2 
(Figures $5 \mathrm{a} \& \mathrm{~b}$ ). The first three data points in each panel represent the proportion of time that participants were looking at the target instrument during each critical time window, while the last data point in each figure shows the proportion of instrument actions. The critical time windows are synchronized to the onset of the object in the prepositional phrase (e.g. "feather" in "You can feel the frog with the feather"). Each time window begins $200 \mathrm{~ms}$ after the onset of the critical linguistic information, to account for the time that it takes to program and launch an eye movement (Allopena, Magnuson, \& Tanenhaus, 1998). Our first time window (33ms-200ms) is called the with-window because it includes gaze shifts that occurred in response to the initial part of the prepositional phrase (with the). Our early-prepositional phrase (PP) window (233ms700ms) includes fixations initiated after the onset of the critical word (feather) and our late-PP window (733ms-1200ms) includes fixations initiated after the utterance ended. Participants could begin anticipating the upcoming noun (the potential instrument or modifier) as soon as they encounter the preposition (with). Thus we might see effects of prosody as early as the withwindow (during the beginning of the with the prepositional phrase). However, Snedeker and Yuan (2008) found that prosody appeared somewhat later: during the early-PP window (e.g., after the critical word) for adults and during the late-PP window (e.g., after the utterance had ended) for preschool-aged children.

The dependent variable in these analyses was whether there was a look to the target instrument during the time window. A fixation or a saccade to the target instrument at any point during the window was coded as "1" and all other trials were coded as "0". Tables 3 and 4 list the results of the ANOVAs for the critical variables for Block 1 and Block 2, respectively.

Block 1. During the with-window (33-200ms, initiation of "with the") there was a significant interaction between Prosody and Diagnosis. To determine the source of the 
interaction, we analyzed the two diagnostic groups separately. In the TD group, there was no effect of Prosody nor any effect of Age or interaction with Age $(|z|$ 's $<1, p$ 's $>.4,|\beta|$ 's $<.2)$. In contrast, for the ASD group there was a reliable effect of Prosody $(z=2.48, p=.01, \beta=.58)$. Participants with ASD looked at the target instrument more often in the instrument prosody condition than in the modifier prosody condition, suggesting that they had anticipated the role of the upcoming noun on the basis of intonation. While Figure 4 suggests that this effect is largely carried by the ASD teens, there was no effect of Age or interaction with Age $(|z|<1, p>.3,|\beta|<$ .3). Thus, the interaction between Prosody and Diagnosis in the with-window indicates that the prosodic manipulation had a more rapid effect on the ASD group than it did on the TD group. In the early-PP window (233-700ms, after onset of critical word feather), there was a large effect of Prosody, with more looks to the target instrument in the instrument prosody condition. There was no interaction with either Age or Diagnosis, suggesting that the use of intonation was similar across the groups of participants. Separate models for each of the groups (child TD, child ASD, teen ASD, teen TD) confirmed that the effect of Prosody was reliable in each of them (see Table 5). Thus we see no evidence that the initial processing of the prepositional phrase differs between children with ASD and their typical peers. This pattern persisted in the late-PP window (733-1200ms, after the utterance had ended). There was a robust effect of Prosody which was reliable in each of the four participant groups (see Table 5).

In sum, children and teens with ASD were able to use prosodic cues to guide their unfolding interpretations of the utterances during the first block of trials. Critically, the one reliable difference between the ASD group and TD controls (the interaction between Diagnosis and Prosody in the with-window, 33-200ms, during the onset of the prepositional phrase) indicated that participants with ASD were making more rapid use of the prosodic information. 
Block 2. The eye movements in Block 2 (Figures 5a \& b) showed a very different pattern. In the with-window (33-200ms), there was a reliable interaction of Prosody and Age but no other effects. To explore this interaction, we conducted separate analyses for the two age groups. In the Teen group there were no reliable effects or interactions $(|z|$ 's $<1.5, p$ 's $>.1,|\beta|$ 's $<$ .4). However, in the Child group, there was a robust reverse prosody effect: those who heard sentences with modifier prosody looked at the target instrument more than those who heard instrument prosody $(z=-3.06, p=.002, \beta=-1.19)$. Furthermore, there was no main effect of Diagnosis or interaction between Prosody and Diagnosis $(|z|$ 's $<.3, p$ 's $>.7,|\beta|$ 's $<.2)$, suggesting that the reverse prosody effect was no larger in the Child-ASD group than in the Child-TD group.

Presumably, these effects are not a result of the prosodic manipulation itself but instead stem from interference from the earlier utterances. The children who had heard instrument prosody in Block 1 continued looking at the target instrument in Block 2, even though they were now hearing modifier prosody. Similarly, the children who had heard modifier prosody in Block 1 continued ignoring the target instrument in Block 2. Thus this effect suggests that the child participants in both groups were predicting the meaning of the utterance on the basis of their initial experiences in the study, and were (at first) failing to notice the prosodic cues that signaled a shift in interpretation.

This difference between the two age groups persists into the early-PP window (233700ms, after critical word), where there is a main effect of Prosody, an effect of Age and an interaction between Prosody and Age. To better understand the interaction, we conducted separate analyses of the children and teens. In the Child group, there was no longer any effect of Prosody, nor was there any effect of or interaction with Diagnosis $(|z|$ 's $<1.6, p$ 's $>.1,|\beta|$ 's $<.3)$. 
In contrast Teen group, there was a robust effect of Prosody $(z=4.63, p<.0001, \beta=.90)$ and no effect of or interaction with Diagnosis $\left(|z|\right.$ 's $<.5, p^{\prime} \mathrm{s}>.5,|\beta|$ 's $\left.<.1\right)$. Analyses of the four groups of participants revealed robust effects of Prosody in ASD-Teen and TD-Teen groups, a marginal effect in the TD-Child group, but no effect in the ASD-Child group (see Table 6).

Finally, in the late-PP window (733-1200ms, after end of utterance) there was a main effect of Prosody in the omnibus analysis and no other effects or interactions. Analyses of the four groups of participants (Table 6) indicated that this effect was large and robust in both of the teen groups and the TD-child group but absent in the ASD-Child group.

In sum, the teens and children show very different processing patterns in the second block. The teens use the prosodic form of the utterance to close in on the correct interpretation of the prepositional phrase in the early-PP window $(230-700 \mathrm{~ms}$, after critical word). In contrast, the children initially predict that the utterance will have the same interpretation as the sentences in the previous block, resulting in reverse-prosody effects in with-window (33-200ms). This effect disappears in the later time windows, suggesting that the children are beginning to revise their interpretation of the sentence. In TD child group, this process eventually results in patterns of fixations and actions that correctly reflect the prosody of the utterance. For the ASD children, revision is less successful, resulting in chance performance.

\section{Discussion}

The results of this experiment answer the questions that we posed in the introduction.

First, we found that children and adolescents with ASD are as likely as TD peers to use prosodic information to resolve syntactic ambiguity, provided that there is no need to revise their interpretation of the utterance or override perseveration. On the initial block of trials, both groups responded correctly about $80 \%$ of the time. Second, the ASD groups were able to use 
prosodic cues to syntax at least as rapidly as TD peers, suggesting that similar comprehension mechanisms were used by both populations. Specifically, in the ASD group prosody had a reliable effect on eye-movements immediately after the onset of the preposition (Block 2, withwindow, 33-200ms), suggesting that they were beginning to anticipate the content and interpretation of the prepositional phrase. This effect was not present in the typical participants in the initial block of trials. Nevertheless, after the onset of the critical word, prosody had a robust effect on interpretation that was similar in all groups (Block 1, early PP-window, 233700ms - after critical word feather). This effect persisted throughout the trial (Block 1, late PPwindow, 733-1200ms - after end of utterance). Third, these results reveal that the developmental changes from 7 to 17, for both TD and ASD children are primarily related to the ability to shift one's interpretation of an ambiguous sentence. In Block 2, both the ASD and TD child groups initially misinterpreted the critical sentence, predicting that it would have the same interpretation as the critical sentences in Block 1. In contrast, the teens were able to quickly use the prosodic cue to shift their interpretation of the utterance and showed no evidence of interference in Block 2. Finally, our findings suggest that younger children with ASD are less able to overcome this interference than their TD peers (Block 2, actions).

In the remainder of this paper we explore: how these results can be reconciled with prior studies of prosody and parsing in ASD, how to account for the perseveratory errors in the child ASD group, how these findings constrain our understanding of the broader prosodic impairment in ASD, what they tell us about typical development, and the limitations of the present study.

\section{Reconciling the Findings on Prosody and Parsing in ASD}

The results of this study are consistent with the prior literature on prosody and parsing in ASD and provide insight into findings that had seemed incompatible. As we noted in the 
introduction, all of the prior studies used tasks in which participants had to shift between two different syntactic structures, creating the potential for interference across trials. We find that the ability to override this interference develops by the age of 7 or 8 in TD children and is delayed in children with ASD, emerging when they reach a verbal age of about 12. This finding suggests that children with ASD will diverge from language-matched TD peers on these tasks when they have verbal mental ages between 8 and 12 years but otherwise perform similarly. This prediction is confirmed for the studies using judgment tasks; studies in which the average verbal age is below 8 (Peppé et al., 2007) or over 13 (Paul et al., 2005; Chevallier et al., 2009) have found no differences between groups, while the one study with sizeable portion of children in this critical developmental window did find a difference between children with ASD and language-matched children with developmental delays (Järvinen-Pasley et al., 2008a).

The Diehl study does not conform to this pattern (Diehl et al., 2008). The participants were very similar to the ASD-Teen group in the present study: they had IQ and language scores within the normal range and were primarily over 12 (11-19 years, M=15;3). Our ASD-Teen Group avoided perseveration and performed as well as TD controls. In contrast, the ASD group in the Diehl study performed worse than their TD peers. We believe that this difference is attributable to the kind of sentences used in their study. As we noted earlier, the difference between the ASD and TD groups in the Diehl study was limited to the condition where prosody was in conflict with the preferred interpretation of the sentence ("Put the dog in the basket... on the star"). In this case, participants must use prosodic structure to revise an initial misinterpretation of the first prepositional phrase (Tanenhaus et al., 1995). In contrast, in the present study the critical prosodic cues always occur before the ambiguous phrase, thus reanalysis is never required. The ability to revise misparsed utterances develops during middle 
childhood and appears to involve executive functions such as cognitive control and working memory (Trueswell et al., 1999; Novick, Trueswell, \& Thompson-Schill, 2005). Thus the group differences in the Diehl study could be attributable to deficits in executive functions and syntactic revision, rather than deficits in prosody comprehension. Critically, our results rule out an alternate interpretation of the prior literature. The discrepancy between the Diehl data and the explicit judgment studies cannot be attributed to differences between action-based tasks and reflective tasks (that might give rise to strategizing); we also employed an act-out paradigm with similar task demands but found no deficits in prosodic processing for adolescents with ASD.

\section{Why Do Children With ASD Have Difficulty Overcoming Interference?}

The one difference that we observed between the ASD and TD groups was the poorer performance on the child ASD group on the second block, which appears to reflect a failure to override interference from the earlier trials. This failure is not absolute. If the children were completely immune to the change in prosody, they would continue responding as they did in the first block, resulting in a reliable reverse prosody effect in their actions. This finding cannot be attributed to the presence of two groups (one that perseverates and one that switches): two-thirds of the ASD-Child group produced both correct and incorrect responses in the second block. Instead, the pattern of performance across these four trials shows that the children with ASD are gradually adjusting their interpretation to match the new prosodic form: children get $78 \%$ of the actions right on block 1, on the first trial after the switch performance drops to $38 \%$ correct, and then gradually recovers reaching $67 \%$ on the final trial. In contrast, for the other three groups performance is above chance on the first switch trial (75\% for ASD teen, 73\% for TD child, and $71 \%$ for TD teen) and does not improve on subsequent trials. Thus between the ages of seven and twelve children with ASD are able to form strong expectations about syntax on the basis of 
prosodic information, but they have difficulty overriding these expectations when prosody changes. Nevertheless, they do detect the change in prosody and over the course of a few trials they shift their interpretation of the ambiguity to match it.

One possible interpretation of this finding is that it reflects a deficit in executive function. Children with ASD perform more poorly than controls on a wide range of executive function measures (for reviews see Hill, 2004; Russo, Flanagan, Iarocci, Berringer, Zelazo \& Burack, 2007). The deficit that is most consistently found is a difficulty switching between different rules on the Wisconsin Card Sorting Task and similar paradigms; persons with ASD tend to perseverate, producing responses that are consistent with the rule that they had learned earlier, much like they did in our prosody task. These deficits are present even in highly-verbal persons with ASD and even when participants are matched on the basis of their verbal abilities (Ambery, Russell, Perry, Morris \& Murphy, 2006; Ozonoff, Pennington, \& Rogers, 1991; Ozonoff et al., 2004; Verte, Guerts, Roeyers, Ooosterlaan, \& Sergeant, 2006). Thus, although we did not collect any information about executive function abilities in our sample, it is possible that the ASD and TD groups differed in this respect, but that the executive function requirements of this task are simple enough that both groups have mastered them by age 13.

\section{Characterizing the Prosodic Deficit in ASD}

The present results also constrain our understanding of the broader prosodic deficit in ASD. If children with ASD can use prosody to determine the syntactic structure of an utterance, it suggests that their other prosodic difficulties are not due to a global deficit in prosodic comprehension, but instead reflect a more circumscribed problem. The literature suggests three possibilities. 


\section{The perception of prosody is intact in ASD and deficits appear only when prosodic} information is used by another process (like pragmatics) which is itself impaired. This hypothesis predicts that people with ASD should have no deficits in using prosody for nonpragmatic functions, when compared to controls with similar lexical and syntactic abilities. This prediction is consistent with most of the prior research. Children with ASD perform as well as language-matched peers in tasks tapping the use of prosody for syntactic comprehension (see above), syntactic production (Paul et al., 2005; Peppé et al., 2007) and lexical comprehension (Chevallier et al, 2009; Grossman et al., 2010; Paul et al., 2005). The findings on the production of lexical stress (reCORD vs. REcord) are less clear: while one study found less accurate production in persons with ASD (Paul et al., 2005), the other found that speakers with ASD were equally accurate (Grossman et al., 2010). This could reflect extraneous demands of the experimental tasks. The Paul study used the reading task similar to that used to study the disambiguation of homographs (the wind blows/wind up the string). In these studies, persons with ASD typically perform worse than matched controls (Frith \& Snowling, 1983; Happé, 1997; Jolliffe \& Baron-Cohen, 1999; Lopez \& Leekam, 2003), because they have difficulty using context to identify the correct meaning (Happé, 1997) or to inhibiting one pronunciation of a string shortly after using another (Hala, Pexman \& Glenwright, 2007).

This hypothesis is also consistent with the prior evidence for a deficit in using prosody for pragmatic purposes, such as determining a speaker's emotional state on the basis of their tone of voice (Golan et al., 2007; Järvinen-Pasley et al., 2008a; Kleinman et al., 2001; Peppé et al., 2007; Rutherford et al., 2002), or using pitch accents to encode the discourse function of a word (Baltaxe \& Guthrie, 1987; McCaleb and Prizant, 1985; Paul et al., 2005; Peppé et al., 2007). One challenge for this hypothesis is accounting for those studies which have failed to find 
deficits in the use of prosody for pragmatic purposes. Many of these null findings may be attributable to ceiling effects, floor effects, or the use of small and heterogeneous samples. For example, performance on the contrastive stress comprehension task used by Peppé and colleagues (2007) is near chance for both groups, suggesting that the task may be too hard for this age group. In other cases, null findings could reflect the boundaries of the pragmatic deficit in ASD. For example, across a wide age range, persons with ASD perform as well as controls at using prosody to distinguish questions from statements (Chevallier et al., 2009; Järvinen-Pasley et al., 2008a; Peppé et al., 2007; Paul et al., 2005) but this pragmatic inference is simple and does not require modeling the speaker's mental state. Pragmatic inferences with this profile (such as scalar implicatures) do not appear to be impaired in highly-verbal ASD (Chevallier, Wilson, Happé \& Noveck, 2010; Pijnacker, Geurts, Van Lambalgen, Kan, Buitelaar \& Hagoort, 2009).

\section{There are impairments in the perception of prosody in ASD, but they affect}

prosodic features that are not needed for prosodic parsing. Theories of prosody generally make a distinction between paralinguistic prosody and prosodic structure. Paralinguistic prosody is the global properties of an utterance (speed, mean pitch, tone of voice) which can provide information about the physiological/emotional state of a speaker. Prosodic structure has two dimensions: intonational phrasing groups words together into prosodic units, while the placement of pitch accents indicates the prominence of units within this structure (Speer \& Ito, 2009; Wagner \& Watson, 2010). Syntactic structure is systematically linked to intonational phrasing but not to pitch prominence (Lee \& Watson, 2011) or paralinguistic prosody. In contrast, accent placement is about how an utterance relates to the prior discourse. This suggests a theoretical possibility: perhaps the use of intonational phrasing is unimpaired in ASD while the use of pitch accents is impaired. 
This theory correctly predicts that children with ASD should do poorly on tasks involving contrastive stress but well on tasks in which intonational boundaries provide syntactic information. This hypothesis is also consistent with the naturalistic production studies which suggest that ASD is characterized by the use of repetitive and simple pitch contours which are produced with more extreme pitch variation (Diehl et al., 2009; Green \& Tobin, 2009; Nadig \& Shaw, 2012). Finally, this hypothesis suggests that pragmatic inferences that depend on paralinguistic prosody (e.g., judgments of emotion or intended audience) may show different patterns of impairment across populations than those that depend on pitch prominence.

The appeal of this hypothesis is its potential to connect deficits in linguistic tasks to deficits in perception. If pitch prominence was primarily signaled by one acoustic parameter (e.g., fundamental frequency) and intonational boundaries by another (e.g., duration or pausing), then deficits in processing accents could arise from atypical sensory processes. This hypothesis is consistent with the literature on auditory perception which suggests that atypical processing of frequency is more common than atypical processing of duration and intensity (Jones et al., 2009; Marco et al., 2011; O’Connor, 2012).

\section{True prosodic deficits in ASD only occur in persons who also have language delays.}

Two lines of reasoning suggest that the nature of the prosodic deficit in ASD might vary with a person's overall level of linguistic functioning. First, because prosody plays a central role in language acquisition and comprehension, it seems unlikely that a child with a broad prosodic deficit would acquire language on the typical developmental timetable. For example, both infants and adults use prosody during speech perception to find the boundaries of words (lexical segmentation, see Cutler, Dahan \& van Donselaar, 1997; Johnson \& Jusczyk, 2001). Consequently, someone who was prosodically insensitive would be expected to have delays in 
vocabulary acquisition (because they have difficulty learning word forms) and spoken language comprehension (because lexical access would be slower).

Second, prosodic deficits in ASD may be more common in participants who have lexical and syntactic delays. Peppé and colleagues (2011) found that children with ASD with a history of preschool language delay performed worse than language-matched controls on most measures of expressive prosody. In contrast, those without early language impairments performed similarly to controls on every measure except imitation. In general, studies in which the ASD participants have mild language delays are more likely to find evidence for prosodic deficits (Järvinen-Pasley et al., 2008a; Peppé et al., 2007) than studies where the participants have language abilities at age level (Chevallier et al., 2009; Chevallier et al., 2011; Grossman et al., 2010; Paul et al., 2005).

\section{What These Findings Tell us About Typical Development}

While the primary goal of the present study was to understand prosodic parsing in ASD, this research also provides novel information about the development of this ability in typical children. First, we found that initial sensitivity to prosody does not change between the ages of four and twelve: on the first block of trials, both the 4-5 year olds in Snedeker \& Yuan (2008) and the 8-12 year olds in the present study acted in accordance with prosody about $75 \%$ of the time. This is remarkable given the dramatic changes in attention, motivation, and education across this age range. It suggests that the present task has few extraneous demands. However, a comparison of the eye-movement data from the first block of trials indicates that school-aged (812 year old) children are faster to use prosody than preschoolers. In preschoolers, the effects of prosody emerged during the late-PP window (500-1000 ms after the critical word), but in older children and adolescents (in the present study) and in adults (in Snedeker \& Yuan, 2008) these 
effects emerged during the early-PP window $(0-500 \mathrm{~ms})$. Thus prosodic parsing becomes more rapid between five and eight years of age, but may not get faster after that time.

Critically, we found that the tendency to perseverate across trials, which is robustly present in 4-5 year olds, has disappeared by school age (7-12 years). This is not because schoolage children do not experience interference across blocks - their early eye-movements suggest that they do-instead it reflects an improved ability to overcome interference and respond in accordance with the prosodic cues. This pattern is reminiscent of the change that occurs in children's ability to revise garden-path sentences. Young children, like adults, use the information that they encounter early in a sentence to determine how to interpret syntactic ambiguities. Adults will revise these commitments on the basis of cues that occur later in the sentence but young children will not (Trueswell et al., 1999). Performance on these tasks improves rapidly at around the age of eight (Trueswell et al., 1999; Weighall, 2008), but no eyemovement data has been published from school-aged children to confirm that revision is involved. Our data fills this gap by providing clear evidence that school-aged children misanalyse this structural ambiguity (with window block 2) and then correctly revise their interpretation (late-PP window after the utterance ended, and actions block 2). Thus our findings suggest that syntactic revision improves substantially at around 8 years of age. This change has been argued to reflect the development of executive functions (specifically cognitive control; see Novick et al., 2005), and the failure to revise in the ASD children, who may have executive function impairments, is consistent with this hypothesis.

Finally, we found that the TD adolescents differed from the TD children in one critical respect: their eye movements suggested that they did not experience prolonged interference when they shifted interpretations. It is unlikely that the adolescents failed to make any prediction 
about the syntactic ambiguity on the basis of the earlier trials; this kind of syntactic priming is a robust feature of comprehension across the lifespan (Thothathiri \& Snedeker, 2008a/2008b). One possibility is that adolescents made predictions but were able to quickly update them as the experiment progressed. If this were the case, the incorrect prediction on the first trial after the switch would be balanced out by correct predictions on subsequent trials, rendering it invisible in the present data. This ability to quickly shift perspectives could be due to an awareness of the ambiguity of the sentence and the expectation that both interpretations will be present in the study. In prior studies using similar materials, adults were typically aware of syntactic ambiguities (Snedeker \& Trueswell, 2003; Snedeker \& Trueswell, 2004).

\section{Limitations}

The present study has a number of limitations which should be considered in assessing its clinical relevance. First, we focused solely on children with strong structural language skills, thus the results may not generalize to the broader population of children with ASD. However, as we noted above, an increasing proportion of children with ASD diagnoses have language abilities within the normal range. Furthermore, this population may be of particular relevance to those working with ASD children in mainstream educational settings. Second, we did not test children under seven and thus we do not know whether the early development of prosodic parsing in ASD deviates from that of TD children. Third, we tested only one of the possible manipulations of prosody, and thus we cannot know whether other aspects of the syntax-prosody interface develop more slowly in ASD, perhaps because they are more subtle or complex. Finally, we did not directly measure executive function (EF). Such measures would be useful to test our hypothesis about the role of EF in switching between responses in the second block of the task. 


\section{Conclusions}

In sum, these results provide a window into developmental changes moment-to-moment prosody processing in individuals with ASD and their TD peers. The subtle but striking differences found in this study highlight the importance of understanding how language comprehension unfolds over time, in addition to the final behavioral responses. To date, only one published study has used the visual-world paradigm to explore moment-to-moment language comprehension in ASD (Brock, Norbury, Einav \& Nation, 2008). The visual-world paradigm provides rich information about how interpretation involves over time with minimal task demands, and thus is well suited to exploring the processes that underlie language comprehension in developmental disorders. The present experiment demonstrates this. The eyemovement data allowed us to conclude that children and adolescents with ASD not only use prosody to resolve ambiguity, but they do so using a mechanism that has a similar temporal profile to the one used by their TD peers. This suggests that prosodic processing in ASD does not involve task-specific strategies, since presumably these would be slower and less efficient. The eye-movement data also clarifies the nature of the difference between TD and ASD children: both groups develop expectations about the utterances on the basis of their experience, but while typical children overcome this initial misanalysis, those with ASD do not. Finally, the eye data clarifies the nature of the developmental changes that occur between childhood and adolescence. If we had only the actions, we might have thought that adolescents with ASD perform better than children with ASD because they are able to resolve interference like TD peers. Our data suggests that adolescents, in both groups, appear to avoid interference altogether. Future studies using this approach will provide a richer understanding of language comprehension in individuals with ASD. 


\begin{tabular}{|c|c|c|c|c|c|c|c|c|}
\hline & $\begin{array}{c}\text { ASD- } \\
\text { Child } \\
M(S D) \\
\text { [range] }\end{array}$ & $\begin{array}{c}\text { TD- } \\
\text { Child } \\
M(S D) \\
\text { [range] }\end{array}$ & $\bar{F}$ & $\bar{p}$ & $\begin{array}{c}\text { ASD-Teen } \\
\text { M (SD) } \\
\text { [range] }\end{array}$ & $\begin{array}{c}\text { TD-Teen } \\
M(S D) \\
\text { [range] }\end{array}$ & $F$ & $\bar{p}$ \\
\hline $\mathrm{N}$ & 24 & 24 & & & 24 & 24 & & \\
\hline $\begin{array}{l}\text { Gender } \\
(\mathrm{M}: \mathrm{F})\end{array}$ & $21: 3$ & $19: 5$ & & & $19: 5$ & $20: 4$ & & \\
\hline $\begin{array}{l}\text { Chron. } \\
\text { Age }\end{array}$ & $\begin{array}{c}10.0 \\
(1.1) \\
{[7-12]}\end{array}$ & $\begin{array}{c}10.3 \\
(1.6) \\
{[7-12]}\end{array}$ & .75 & .39 & $\begin{array}{c}15.3 \\
(1.4) \\
{[12-17]}\end{array}$ & $\begin{array}{c}15.1 \\
(1.5) \\
{[12-17]}\end{array}$ & .21 & .65 \\
\hline $\begin{array}{l}\text { Full Scale } \\
\text { IQ }\end{array}$ & $\begin{array}{c}113.3 \\
(16.5) \\
{[88-148]}\end{array}$ & $\begin{array}{c}113.8 \\
(13.6) \\
{[88-136]}\end{array}$ & .02 & .90 & $\begin{array}{c}111.3 \\
(13.7) \\
{[83-141]}\end{array}$ & $\begin{array}{c}110.0 \\
(11.7) \\
{[91-135]}\end{array}$ & .13 & .72 \\
\hline Verbal IQ & $\begin{array}{c}113.7 \\
(16.5) \\
{[85-151]}\end{array}$ & $\begin{array}{c}113.5 \\
(13.6) \\
{[89-136]}\end{array}$ & .01 & .98 & $\begin{array}{c}112.8 \\
(16.4) \\
{[85-143]}\end{array}$ & $\begin{array}{c}109.9 \\
(12.0) \\
{[82-135]}\end{array}$ & .47 & .50 \\
\hline $\begin{array}{l}\text { CELF-IV } \\
\text { Receptive } \\
\text { Language }\end{array}$ & $\begin{array}{c}104.5 \\
(18.0) \\
{[81-140]}\end{array}$ & $\begin{array}{c}107.5 \\
(13.1) \\
{[85-128]}\end{array}$ & .42 & .52 & $\begin{array}{c}105.5 \\
(12.2) \\
{[82-125]}\end{array}$ & $\begin{array}{c}108.3 \\
(11.0) \\
{[88-130]}\end{array}$ & .67 & .41 \\
\hline
\end{tabular}

Table 1. Descriptive characteristics of the sample by diagnostic group. Participants younger than 12.5 were included in the child groups, and those above 12.5 were included in the teen groups. IQ was measured using either the Wechsler Abbreviated Scale of Intelligence (Wechsler, 1999) or the Differential Ability Scales (Elliott, 1990). CELF-IV=Clinical Evaluation of Language Fundamentals, 4th edition (Semel et al., 2003). ASD = autism spectrum disorder. TD = typically developing comparison group. 
Block 1

Block 2

Prosody

\begin{tabular}{|l|l|}
\hline$\beta=2.15, \mathrm{z}=8.62, \mathrm{p}<.0001^{* *}$ & $\beta=1.41, \mathrm{z}=5.99, \mathrm{p}<.0001^{* * *}$ \\
\hline
\end{tabular}

Age (Child or Teen)

$\beta=.01, z=.04, p=.97$

$\beta=-.15, z=-.65, p=.52$

Diagnosis (ASD or TD)

$\beta=.06, \mathrm{z}=.25, \mathrm{p}=.81$

$\beta=.06, \mathrm{z}=.26, \mathrm{p}=.80$

Prosody * Age

$\beta=.16, z=.68, p=.51$

$\beta=.48, \mathrm{z}=2.05, \mathrm{p}=.04^{*}$

Prosody * Diagnosis

$\beta=-.17, z=-.68, p=.50$

$\beta=-.48, z=-2.07, p=.04^{*}$

Age * Diagnosis

$\beta=.07, z=.29, p=.77$

$\beta=.15, z=.65, p=.51$

Prosody * Diagnosis * Age

$\beta=-.13, z=-.54, p=.59$

$\beta=.33, \mathrm{z}=1.40, \mathrm{p}=.16$

379 observations, 8 verbs, 96 Ss

381 observations, 8 verbs, $96 \mathrm{Ss}$

Table 2. Analysis of actions on objects carried out by participants by block of presentation. The dependent variable is whether the action involved the instrument. $\mathrm{ASD}=$ autism spectrum disorder. $\mathrm{TD}=$ typically developing comparison group. Black borders indicate reliable effects. 


\begin{tabular}{|c|c|c|c|}
\hline & With-window (33-200ms) & Early-PP window (233-700ms) & Late-PP window (733-1200ms) \\
\hline Age (Child or Teen) & $\beta=.06, z=.35, p=.72$ & $\beta=.20, z=1.40, p=.16$ & $\beta=.29, z=1.73, p=.08$ \\
\hline Prosody $*$ Age & $\beta=-.11, z=-.70, p=.48$ & $\beta=.13, z=.88, p=.38$ & $\beta=-.15, z=-.89, p=.37$ \\
\hline Prosody $*$ Diagnosis & $\beta=.33, z=2.09, p=.04 *$ & $|\beta|<.01, z=-.04, p=.99$ & $\beta=-.30, z=-1.80, p=.07$ \\
\hline Age * Diagnosis & $\beta=.17, z=1.12, p=.26$ & $\beta=-.04, z=-.26, p=.80$ & $\beta=-.22, z=-1.31, p=.19$ \\
\hline Prosody $*$ Diagnosis $*$ Age & $\beta=.05, z=.35, p=.73$ & $\beta=.18, z=1.29, p=.20$ & $\beta=.31, z=1.87, p=.06$ \\
\hline
\end{tabular}

376 observations, 8 verbs, $96 \mathrm{Ss} 375$ observations, 8 verbs, $96 \mathrm{Ss} \quad 345$ observations, 8 verbs, $96 \mathrm{Ss}$

Table 3. Temporal analyses of gaze fixations for Block 1. The dependent variable is whether there was a look to the target instrument during that time window. $\mathrm{ASD}=$ autism spectrum disorder. $\mathrm{TD}=$ typically developing comparison group. $\mathrm{PP}=$ prepositional phrase. Black borders indicate reliable effects. 


\begin{tabular}{|c|c|c|c|}
\hline & With-window (33-200ms) & Early-PP window (233-700ms) & Late-PP window (733-1200ms) \\
\hline Prosody & $\beta=-.42, z=-1.80, p=.07$ & $\beta=.54, z=4.36, p<.0001^{* *}$ & $\beta=.67, z=4.57, p<.0001^{* *}$ \\
\hline Age (Child or Teen) & $\beta=.45, z=1.93, p=.054$ & $\beta=.25, z=2.02, p=.04^{*}$ & $\beta=.07, z=.50, p=.62$ \\
\hline $\begin{array}{l}\text { Diagnosis (ASD or } \\
\text { TD) }\end{array}$ & $\beta=.02, z=.09, p=.93$ & $\beta=-.01, z=-.11, p=.91$ & $\beta=-.13, z=-.90, p=.37$ \\
\hline Prosody * Age & $\beta=.78, z=3.31, p=.0009^{*}$ & $\beta=.31, z=2.48, p=.01^{*}$ & $\beta=.07, z=.49, p=.63$ \\
\hline Prosody * Diagnosis & $\beta=-.03, z=-.11, p=.92$ & $\beta=-.17, z=-1.40, p=.16$ & $\beta=-.03, z=-.19, p=.85$ \\
\hline Age $*$ Diagnosis & $\beta=-.09, z=-.38, p=.70$ & $\beta=.09, z=.77, p=.44$ & $\beta=.14, z=.99, p=.32$ \\
\hline $\begin{array}{l}\text { Prosody * Diagnosis } \\
* \text { Age }\end{array}$ & $\beta=.08, z=.34, p=.70$ & $\beta=.09, z=.73, p=.46$ & $\beta=.09, z=.59, p=.56$ \\
\hline
\end{tabular}

370 observations, 8 verbs, 96 Ss 365 observations, 8 verbs, 96 Ss $\quad 315$ observations, 8 verbs, 93 Ss

Table 4. Temporal analysis of fixations for Block 2. The dependent variable is whether there was a look to the target instrument during that time window. $\mathrm{ASD}=$ autism spectrum disorder. $\mathrm{TD}=$ typically developing comparison group. $\mathrm{PP}=$ prepositional phrase. $\mathrm{Black}$ borders indicate reliable effects. 


TD-Child ASD-Child TD-Teen ASD-Teen

$\begin{array}{ccccc}\text { With-Window } & \beta=.09 & \beta=.66 & \beta=-.23 & \beta=.52 \\ (33-200 \mathrm{~ms}) & \mathrm{z}=.33 & \mathrm{z}=1.44 & \mathrm{z}=-.73 & \mathrm{z}=1.78 \\ & \mathrm{p}=.75 & \mathrm{p}=.15 & \mathrm{p}=.46 & \mathrm{p}=.08 \\ \text { Early-PP } & \beta=1.02 & \beta=.79 & \beta=.88 & \beta=1.64 \\ \text { Window } & \mathrm{z}=3.83 & \mathrm{z}=2.71 & \mathrm{z}=3.78 & \mathrm{z}=3.78 \\ \text { (233-700ms) } & \mathrm{p}=.0001^{*} & \mathrm{p}=.007^{*} & \mathrm{p}=.0002^{*} & \mathrm{p}=.0002^{*} \\ & & & \\ & \beta=2.94 & \beta=.94 & \beta=.99 & \beta=1.10 \\ \text { Late-PP Window } & \mathrm{z}=4.25 & \mathrm{z}=3.15 & \mathrm{z}=4.11 & \mathrm{z}=3.80 \\ (733-1200 \mathrm{~ms}) & \mathrm{p}<.0001^{* *} & \mathrm{p}=.002^{*} & \mathrm{p}<.0001^{* *} & \mathrm{p}=.0001^{*} \\ & & & & \\ & \beta & & \beta=2.43 & \beta=2.06 \\ \text { Actions } & \mathrm{z}=3.74 & \mathrm{z}=4.33 & \mathrm{z}=5.34 & \mathrm{z}=4.19 \\ & \mathrm{p}=.0002^{*} & \mathrm{p}<.0001^{* *} & \mathrm{p}<.0001^{* *} & \mathrm{p}<.0001^{* *}\end{array}$

Table 5. The effect of Prosody within each group in Block 1. ASD=autism spectrum disorder. TD=typically developing comparison group. $\mathrm{PP}=$ prepositional phrase. 
(33-200ms)

Early-PP

Window

(233-700ms)

Late-PP Window
$(733-1200 \mathrm{~ms})$

$\begin{array}{cc} & \beta=1.60 \\ \text { Actions } & \mathrm{z}=4.11 \\ \mathrm{p} & <.0001 * *\end{array}$

\section{TD-Child}

$$
\begin{gathered}
\beta=-1.31 \\
z=-1.47 \\
p=.14
\end{gathered}
$$

\section{ASD-Child}

$$
\begin{aligned}
& \beta=-1.26 \\
& z=-2.36 \\
& p=.02 *
\end{aligned}
$$

$$
\begin{gathered}
\beta=.53 \\
z=1.94 \\
p=.053
\end{gathered}
$$

$$
\begin{gathered}
\beta=.74 \\
\mathrm{z}=2.91 \\
\mathrm{p}=.004^{*}
\end{gathered}
$$

$\mathrm{p}<.0001^{* *}$ $\beta=-.03$

$\mathrm{z}=-.12$

$\mathrm{p}=.90$

$\beta=.65$

$\mathrm{z}=1.48$

$\mathrm{p}=.14$

$$
\begin{aligned}
& \beta=.08 \\
& \mathrm{z}=.23 \\
& \mathrm{p}=.82
\end{aligned}
$$

TD-Teen

ASD-Teen

Table 6. The effect of Prosody within each group in Block 2. ASD=autism spectrum disorder. TD=typically developing comparison group. $\mathrm{PP}=$ prepositional phrase.

$$
\begin{array}{cc}
\beta=.29 & \beta=.42 \\
\mathrm{z}=.72 & \mathrm{z}=1.34 \\
\mathrm{p}=.47 & \mathrm{p}=.18 \\
& \\
\beta=1.14 & \beta=.74 \\
\mathrm{z}=3.23 & \mathrm{z}=3.25 \\
\mathrm{p}=.001^{*} & \mathrm{p}=.001^{*} \\
& \\
\beta=.63 & \beta=.85 \\
\mathrm{z}=2.60 & \mathrm{z}=2.36 \\
\mathrm{p}<.01^{*} & \mathrm{p}=.02^{*} \\
& \\
\beta=1.84 & \beta=2.15 \\
\mathrm{z}=3.86 & \mathrm{z}=8.62 \\
\mathrm{p}=.0001^{*} & \mathrm{p}<.0001^{* *}
\end{array}
$$




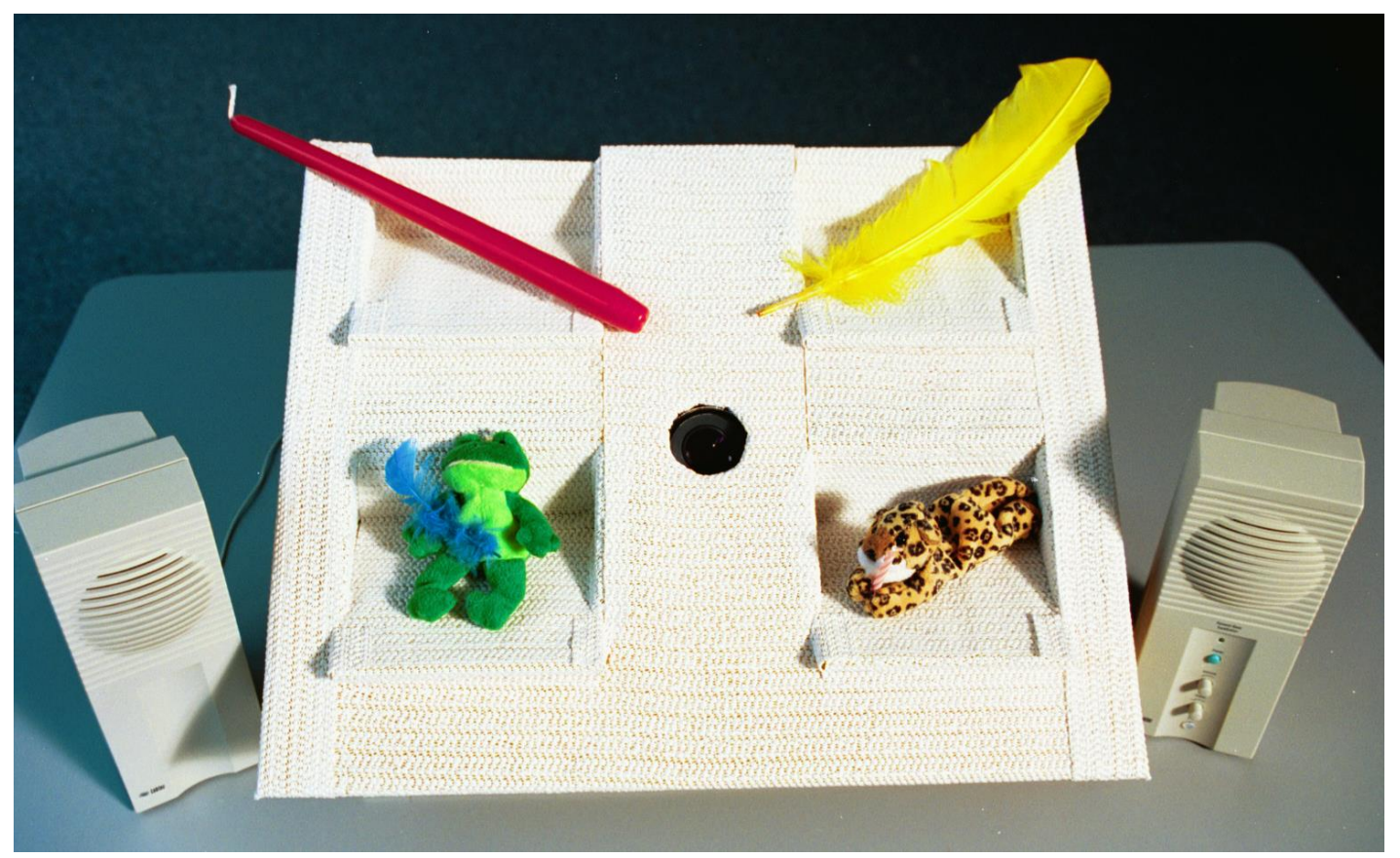

Figure 1. Sample trial in experimental setup. The setup would be accompanied by the utterance "You can feel the frog with the feather." The feather represents the target instrument, the frog (holding a feather) is the target animal, the feather that the frog is holding is the mini-instrument, and the candle and the leopard (holding a candle) are the distracter instrument and the distracter animal, respectively. 


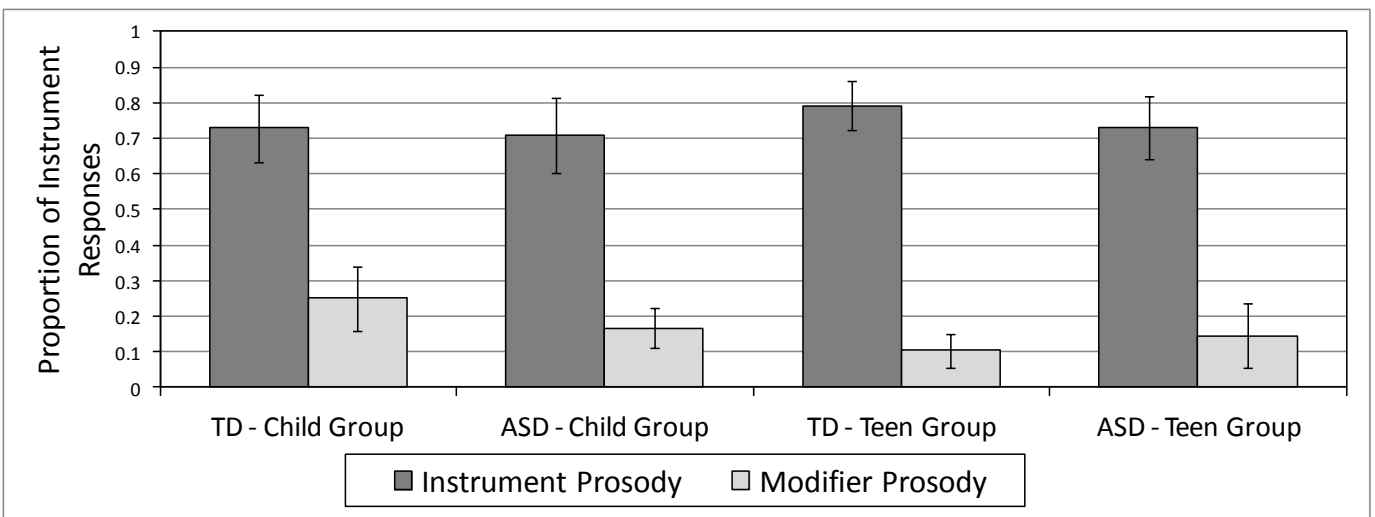

Figure 2. Actions in Block 1. The proportion of instrument responses in Block 1, by group. We would expect that instrument prosody would elicit a large number of instrument responses, whereas the modifier prosody would elicit few instrument responses. $\mathrm{ASD}=$ autism spectrum disorder. $\mathrm{TD}=$ typically developing comparison group. 


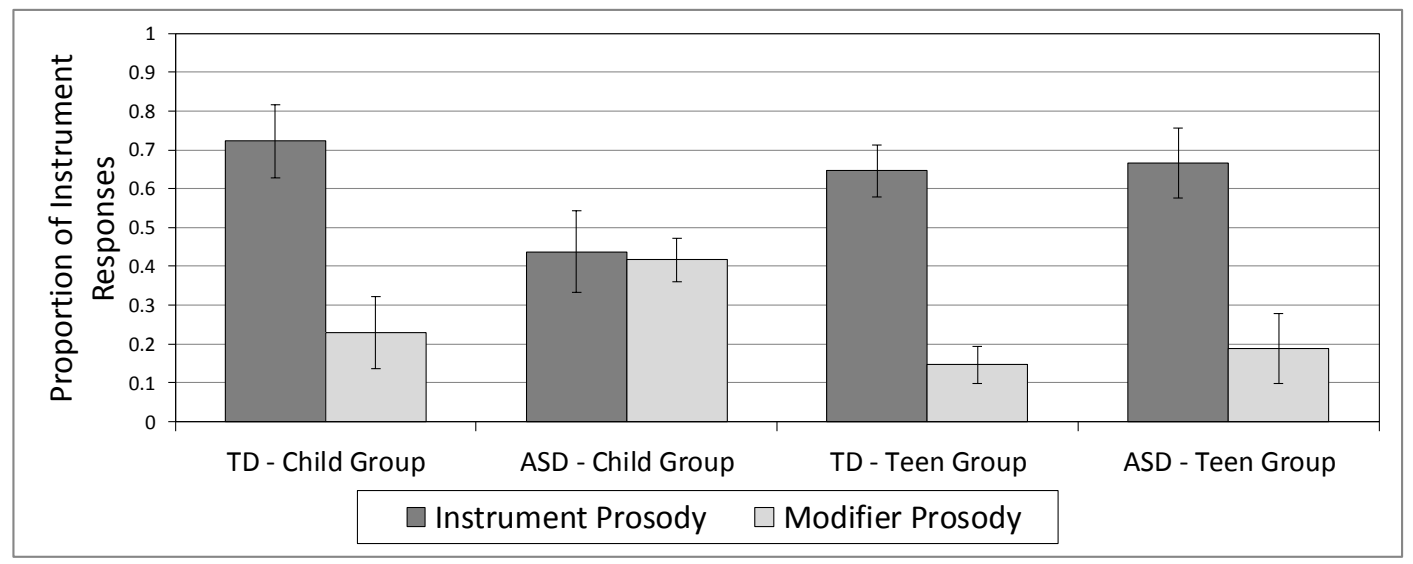

Figure 3. Actions in Block 2. The proportion of instrument responses in Block 2, by group. We would expect that instrument prosody would elicit a large number of instrument responses, whereas the modifier prosody would elicit few instrument responses. $\mathrm{ASD}=$ autism spectrum disorder. $\mathrm{TD}=$ typically developing comparison group. 
A. Child Groups Block 1

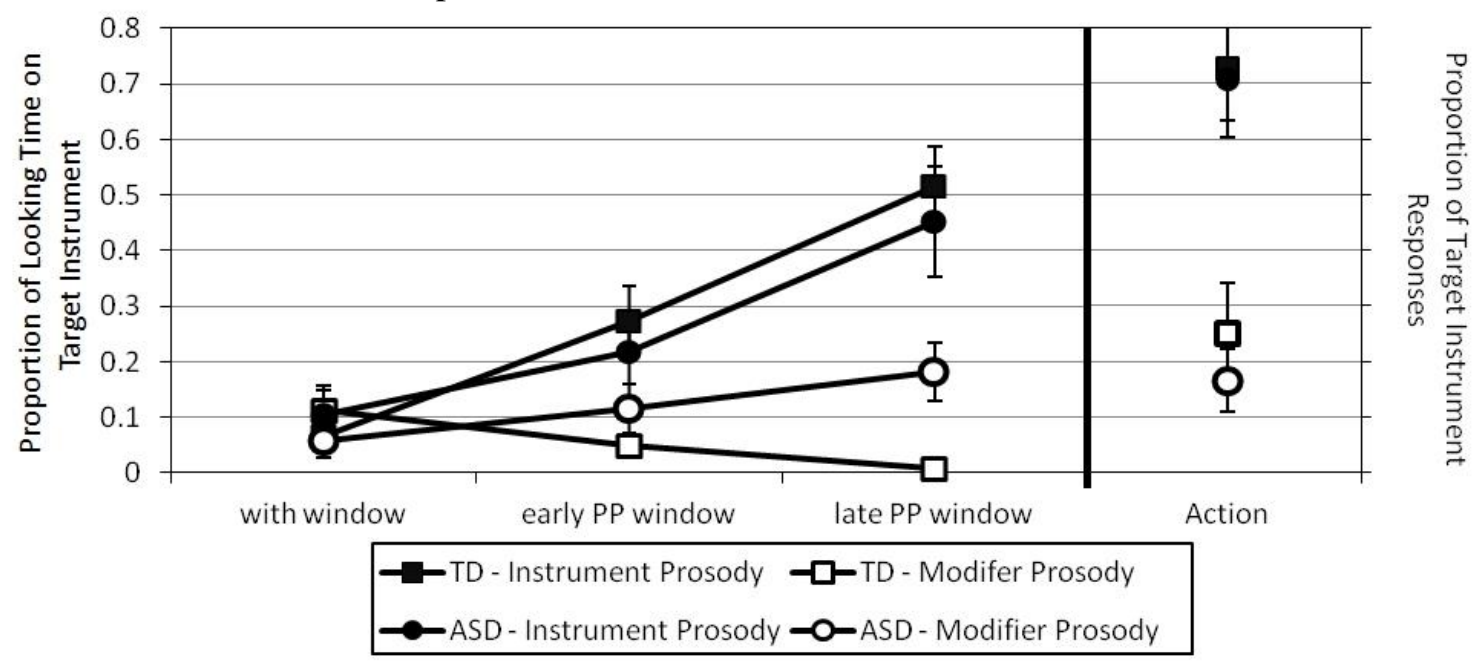

B. Teen Groups Block 1

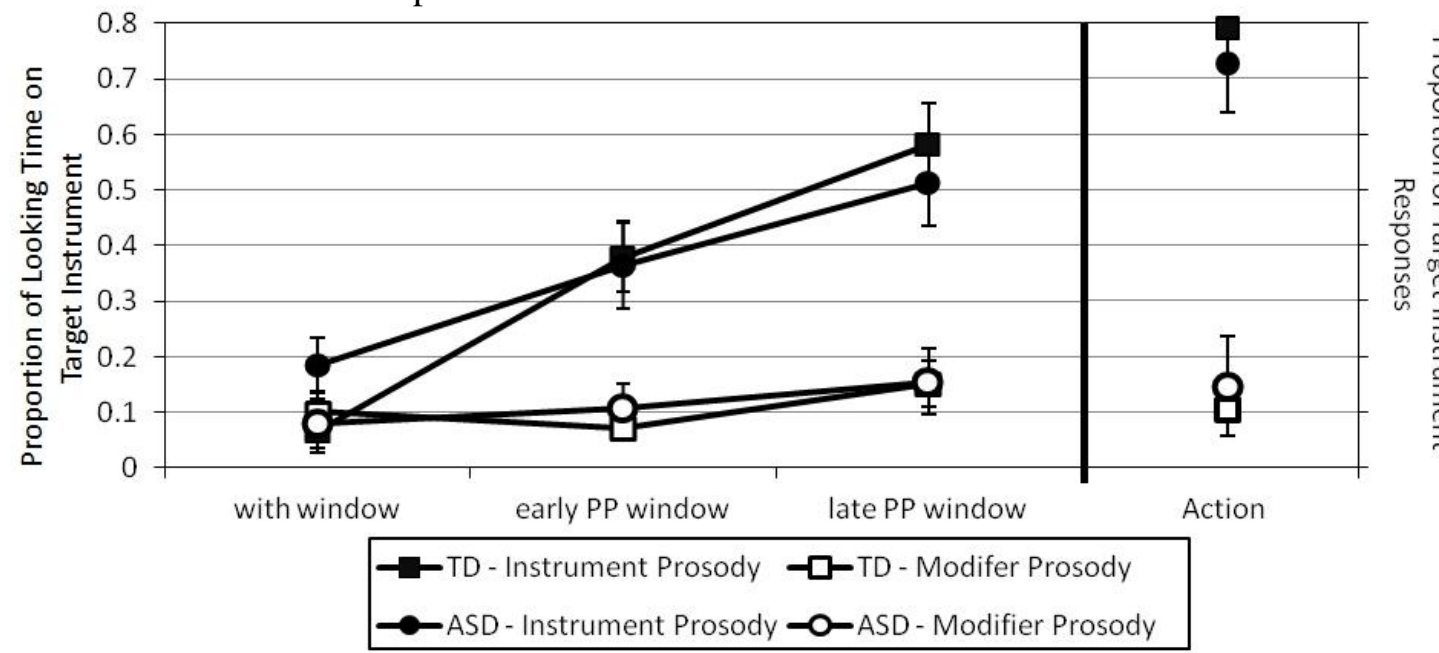

Figure 4. Target instrument looking time relative to the ambiguous prepositional phrase in Block 1. (a) the responses of the child groups (8-12.5 yrs), and (b) the responses of the teen groups (12.5-17 yrs). Action responses are included in the right window for comparison. $\mathrm{ASD}=$ autism spectrum disorder. $\mathrm{TD}=$ typically developing comparison group. $\mathrm{PP}=$ prepositional phrase. With window represents 33-200ms period during the beginning of the prepositional phrase "with the." Early-PP Window represents 233$700 \mathrm{~ms}$ period after onset of "feather." Late-PP window represents $733-1200 \mathrm{~ms}$ after the utterance had ended. 
A. Child Groups Block 2

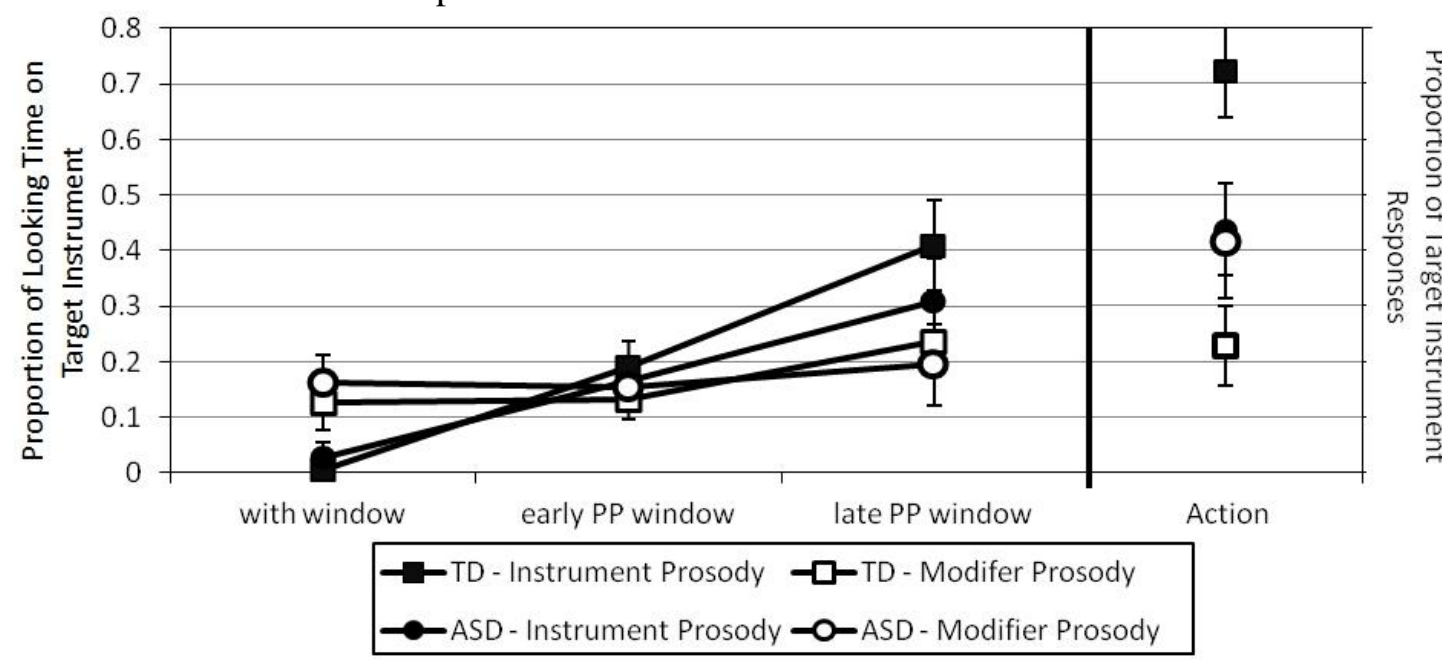

B. Teen Groups Block 2

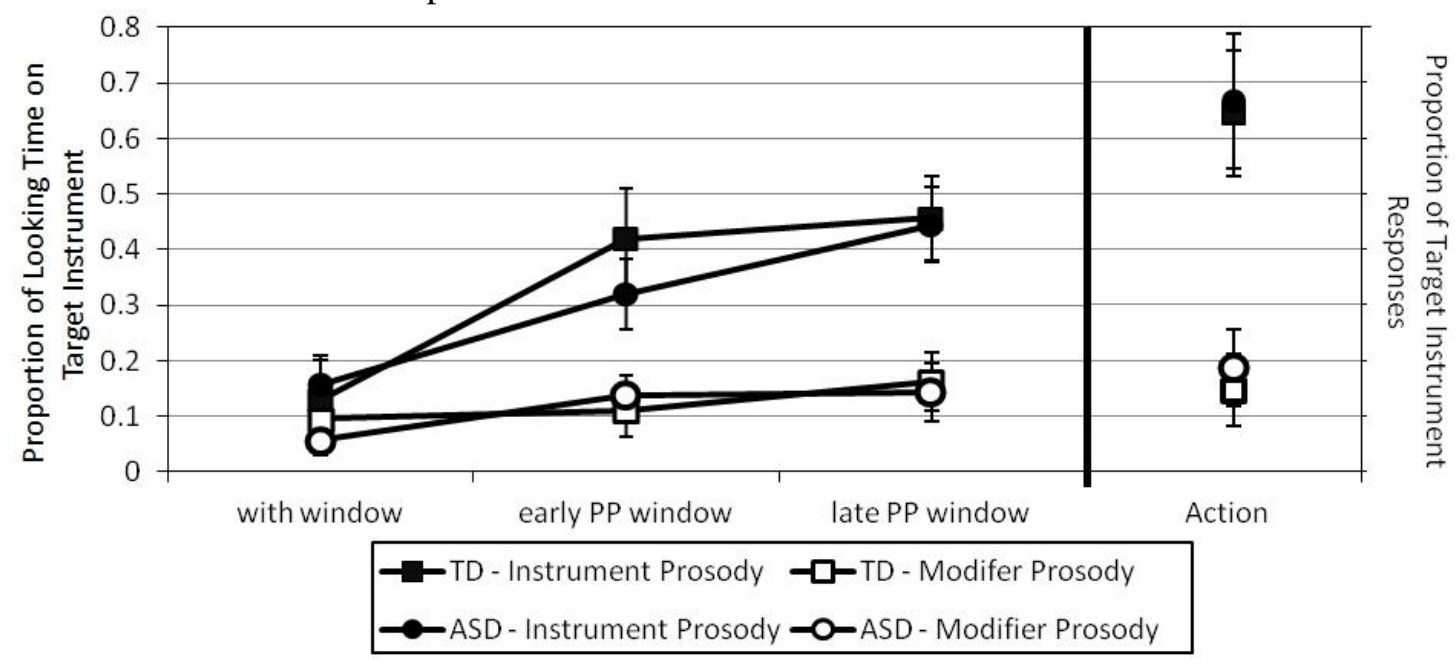

Figure 5. Target instrument looking time relative to the ambiguous prepositional phrase in Block 2. (a) the performance of the child groups (8-12.5 yrs), and (b) the performance of the teen groups (12.5-17 yrs). Action responses are included in the right panel for comparison. $\mathrm{ASD}=$ autism spectrum disorder. $\mathrm{TD}=$ typically developing comparison group. $\mathrm{PP}=$ prepositional phrase. With window represents 33-200ms period during the beginning of the prepositional phrase "with the." Early-PP Window represents 233$700 \mathrm{~ms}$ period after onset of "feather." Late-PP window represents $733-1200 \mathrm{~ms}$ after the utterance had ended. 


\section{References}

Adachi, T., Koedac, T., Hirabayashi, S., Maeoka, Y., Shiota, M., Wright, E.C., Wada, A. (2004). The metaphor and sarcasm scenario test: a new instrument to help differentiate high functioning pervasive developmental disorder from attention deficit/hyperactivity disorder. Brain and Development, 26, 301-306.

Adams, C., Green, J., Gilchrist, A., \& Cox, A. (2002). Conversational behaviour of children with Asperger syndrome and conduct disorder. Journal of Child Psychology and Psychiatry, 43, 679-690.

Allopena, P. D., Magnuson, J. S., \& Tanenhaus, M. K. (1998). Tracking the time course of spoken word recognition using eye movements: Evidence for continuous mapping models. Journal of Memory and Language, 38, 419-439.

Ambery, F., Russell, A., Perry, K., Morris, R., \& Murphy, D. (2006). Neuropsychological functioning in adults with Asperger syndrome. Autism, 10, 551-564.

American Psychiatric Association. (2000). Diagnostic and statistical manual of mental disorders, text revision (4th ed.). Washington, D.C.: APA.

Baltaxe, C. A. M. (1984). Use of contrastive stress in normal, aphasic, and autistic children. Journal of Speech and Hearing Research, 27, 97-105.

Baltaxe, C, \& Guthrie, D. (1987). The use of primary sentence stress by normal, aphasic, and autistic children. Journal of Autism and Developmental Disorders, 17, 255-271.

Beckman, M. E. (1996). The parsing of prosody. Language and Cognitive Processes, 11, $17-67$. 
Brock, J., Norbury, C.F., Einav, S., \& Nation, K. (2008). Do individuals with autism process words in context? Evidence from language-mediated eye-movements. Cognition, 108, 896-904.

Chevallier, C., Noveck, I., Happé, F., \& Wilson, D. (2011). What's in a voice? Prosody as a test case for the Theory of Mind account of autism. Neuropsychologia, 49, 507-517.

Chevallier, C., Noveck, I., Happé, F., \& Wilson, D. (2009). From acoustics to grammar: Perceiving and interpreting grammatical prosody in adolescents with asperger syndrome. Research in Autism Spectrum Disorders, 3, 502-516.

Chevallier, C., Wilson, D., Happé, F. \& Noveck, I. (2010) Scalar inferences in Autism Spectrum Disorders. Journal of Autism and Developmental Disorders, 40, 1104-1117.

Choi, Y., \& Mazuka, R. (2003). Young children's use of prosody in sentence parsing. Journal of Psycholinguistic Research, 32, 197-217.

Christophe, A., Millotte, S., Bernal, S. \& Lidz, J. (2008). Bootstrapping lexical and syntactic acquisition. Language and Speech, 51, 61-75.

Cutler, A. D., Dahan, D., \& van Donselaar, W. (1997). Prosody in the comprehension of spoken language: A literature review. Language and Speech, 40, 141-201.

Diehl, J. J., Bennetto, L., Watson, D., Gunlogson, C., \& McDonough, J. (2008). Resolving ambiguity: A psycholinguistic approach to understanding prosody processing in high-functioning autism. Brain and Language, 106, 144-152.

Diehl, J.J., \& Paul, R. (2012). Acoustic differences in the imitation of prosodic patterns in children with autism spectrum disorders. Research in Autism Spectrum Disorders, 6, 123-134. 
Diehl, J. J., Watson, D. G., Bennetto, L., McDonough, J., \& Gunlogson, C. (2009). An acoustic analysis of prosody in high-functioning autism. Applied Psycholinguistics, 30, 385-404.

Elliott, C. D. (1990). Differential ability scales. San Diego: Harcourt Brace Jovanovich.

Frith, U., \& Snowling, M. (1983). Reading for meaning and reading for sound in autistic and dyslexic children. British Journal of Developmental Psychology, 1, 329-342.

Ghaziuddin, M., \& Gerstein, L. (1996). Pedantic speaking style differentiates asperger syndrome from high-functioning autism. Journal of Autism \& Developmental Disorders, 26(6), 585-595.

Golan, O., Baron-Cohen, S., Hill, J. J., \& Rutherford, M. D. (2007). The Reading the Mind in the Voice Test—Revised: A study of complex emotion recognition in adults with and without autism spectrum conditions. Journal of Autism and Developmental Disorders, 37, 1096-1106.

Green, H. \& Tobin, Y. (2009). Prosodic analysis is difficult - but worth it: A study in High Functioning Autism. International Journal of Speech-Language Pathology, 11, 308-315.

Grossman, R. B., Bemis, R. H., Plesa Skwerer, D., \& Tager-Flusberg, H. (2010). Lexical and affective prosody in children with high-functioning autism. Journal of Speech, Language, and Hearing Research, 53, 778-793.

Hala, S., Pexman, P.M., \& Glenwright, M. (2007). Priming the meaning of homographs in typically developing children and children with autism. Journal of Autism and Developmental Disorders, 37, 329-340. 
Happé, F. (1997). Central coherence and theory of mind in autism: Reading homographs in context. British Journal of Developmental Psychology, 15, 1-12.

Hill, E. (2004). Executive Dysfunctions in Autism. Trends in Cognitive Sciences, 8, 2632.

Ito, K. \& Speer, S. R. (2008). Anticipatory effect of intonation: Eye movements during instructed visual search. Journal of Memory and Language, 58, 541-573.

Järvinen-Pasley, A. M., Peppé, S., King-Smith, G., \& Heaton, P. (2008a). The relationship between form and function level receptive prosodic abilities in autism. Journal of Autism and Developmental Disorders, 38, 1328-1340.

Johnson, E. K. \& Jusczyk, P. W. (2001). Word segmentation by 8-month-olds: When speech cues count more than statistics. Journal of Memory and Language, 44, 548567.

Jolliffe, T.-D., \& Baron-Cohen, S. (1999). Linguistic processing in high-functioning adults with autism or Asperger syndrome: Is local coherence impaired? Cognition, 71, 149-185.

Jones, C. R., Happé, F., Baird, G., Simonoff, E., Marsden, A. J., Tregay, J. et al. (2009). Auditory discrimination and auditory sensory behaviours in ASDs. Neuropsychologia, $47,2850-2858$.

Joseph, R. M., Tager-Flusberg, H., \& Lord, C. (2002). Cognitive profiles and socialcommunicative functioning in children with autism spectrum disorder. Journal of Child Psychology and Psychiatry, 43, 807-821.

Kanner, L. (1943). Autistic disturbances of affective contact. The Nervous Child, 2, $217-$ 250. 
Kelley, E., Paul, J., Fein, D., \& Naigles, L. (2006). Residual language deficits in children with a history of autism. Journal of Autism and Developmental Disorders, 36, $807-$ 828.

Kjelgaard, M. M. \& Tager-Flusberg, H. (2001). An investigation of language impairment in autism: Implications for genetic subgroups. Language and Cognitive Processes, 16, 287-308.

Kleinman, J., Marciano, P. L., \& Ault, R. L. (2001). Advanced theory of mind in highfunctioning adults with autism. Journal of Autism \& Developmental Disorders, 31, 2936.

Klin, A., Jones, W., Schultz, R., \& Volkmar, F. (2003). The enactive mind, or from actions to cognition: lessons from autism. Philosophical Transactions of the Royal Society B: Biological Science, 358, 345-360.

Kujala, T., Aho, E., Lepistö, T., Jansson-Verkasalo, E., Nieminen-von Wendt, T., von Wendt, L., \& Näätänen, R. (2007). Atypical pattern of discriminating sound features in adults with Asperger syndrome as reflected by the mismatch negativity. Biological Psychology, 75, 109-114.

Kujala, T., Kuuluvainen, S., Saalasti, S., Jansson-Verkasalo, E., von Wendt, L. \& Lepistö, T. (2010). Speech-feature discrimination in children with Asperger syndrome as determined with the multi-feature mismatch negativity paradigm. Clinical Neurophysiology, 121, 1410-1419.

Le Sourn-Bissaoui, S., Caillies, S, Gierski, F., \& Motte, J. (2009). Inference processing in adolescents with Asperger syndrome: Relationship with theory of mind abilities. Research in Autism Spectrum Disorders, 3, 797-808. 
Lee, E.-K.. \& Watson, D. G. (2011). Effects of pitch accents in attachment ambiguity resolution. Language and Cognitive Processes, 26, 262-297.

Lepistö, T., Silokallio, S., Nieminen-von Wendt, T. Alku, P., Näätänen, R., \& Kujala, T. (2006). Auditory perception and attention as reflected by the brain event-related potentials in children with Asperger syndrome. Clinical Neurophysiology, 117, 21612171.

Lopez, B., \& Leekam, S. R. (2003). Do children with autism fail to process information in context? Journal of Child Psychology \& Psychiatry, 44, 285-300.

Lord, C., \& Paul, R. (1997). Language and communication in autism. In D. Cohen \& F. Volkmar (Eds.), Handbook of autism and pervasive developmental disorders (pp. 195225). New York: Wiley.

Lord, C., Risi, S., Lambrecht, L., Cook, E. H., Leventhal, B. L., DiLavore, P. C., Pickles, A., \& Rutter, M. (2000). Autism diagnostic observational schedule-generic: A standard measure of social and communication deficits associated with the spectrum of autism. Journal of Autism and Developmental Disorders, 30, 205-223.

Lord, C., Risi, S., \& Pickles, A. (2004). Trajectory of language development in autism spectrum disorders. In M. L. Rice, \& S. F. Warren (Eds.), Developmental language disorders (pp. 7-30). Mahwah, N.J.: Lawrence Erlbaum Associates.

Loukusa, S., Leionen, E., Kuusikko, S., Jussila, K., Mattila, M., Ryder, N., Ebeling, H., \& Moilanen, I. (2007). Use of context in pragmatic language comprehension by children with Asperger syndrome or high-functioning autism. Journal of Autism and Developmental Disorders, 37, 1049-1059. 
Marco, E. J., Hinkley, L. B., Hill, S. S. \& Nagarajan, S. S. (2011). Sensory processing in autism: A review of neurophysiologic findings. Pediatric Research, 69, 48R-54R.

Martin, I., \& McDonald, S. (2004). An exploration of causes of non-literal language problems in individuals with Asperger syndrome. Journal of Autism and Developmental Disorders, 34, 311-328.

Mazuka, R., Jincho, N., \& Oishi, H. (2009). Development of executive control and language processing. Language and Linguistic Compass, 3, 59-89.

McCaleb, P., \& Prizant, B. (1985). Encoding of new versus old information by autistic children. Journal of Speech and Hearing Disorders, 50, 226-230.

MacKay, G., \& Shaw, A. (2004). A comparative study of figurative language in children with autism spectrum disorder. Child Language Teaching \& Therapy, 20, 13-32.

Mehler, J., Jusczyk, P. W., Lambertz, G., Halsted, N., Bertoncini, J., \& Amiel-Tison, C. (1988). A precursor of language acquisition in young infants. Cognition, 29, 143-178.

Morgan, J. L. (1996). Prosody and the roots of parsing. In P. Warren (Ed.), Prosody and parsing. (pp. 69-106). United Kingdom: Psychology Press.

Nadig, A., \& Shaw, H. (2012). Acoustic and perceptual measurement of expressive prosody in high-functioning autism: Increased pitch range and what it means to listeners. Journal of Autism and Developmental Disorders, 42, 499-511.

Nappa, R. \& Snedeker, J. (2012). A surprising contrast: Children with autism spectrum disorders use contrastive stress to identify new referents but not to establish a contrast set. Paper presented at the 37th annual Boston University Conference on Language Development (BUCLD), Boston, MA, November 2012 
Novick, J. M., Trueswell, J. C., \& Thompson-Schill, S. L. (2005). Cognitive control and parsing: Re-examining the role of Broca's area in sentence comprehension. Journal of Cognitive, Affective, and Behavioral Neuroscience, 5, 263-281.

O'Connor, K. (2012). Auditory processing in autism spectrum disorder: A review. Neuroscience and Biobehavioral Reviews, 36, 836-854.

Ozonoff, S., Cook, I., Coon, H., Dawson, G., Joseph, R. M., Klin, A., McMahon, W.M., Minshew, N., Munson, J.A., Pennington, B.F., Rogers, S.J., Spence, M.A., TagerFlusberg, H., Volkmar, F.R., \& Wrathall, D. (2004). Performance on Cambridge neuropsychological test automated battery subtests sensitive to frontal lobe function in people with autistic disorder: Evidence from the collaborative programs of excellence in autism network. Journal of Autism \& Developmental Disorders, 34, 139-150.

Ozonoff, S., Pennington, B., \& Rogers, S. (1991). Executive function deficits in highfunctioning autistic individuals: Relationship to theory of mind. Journal of Child Psychology and Psychiatry, 32, 1081-1105.

Paul, R., Augustyn, A., Klin, A., \& Volkmar, F. (2005). Perception and production of prosody by speakers with autism spectrum disorders. Journal of Autism \& Developmental Disorders, 35, 205-220.

Paul R., Orlovski S., Marchinko H., \& Volkmar F. (2009). Conversational behaviors in youth with high-functioning autism and Asperger syndrome. Journal of Autism and Developmental Disorders, 39, 115-125.

Peppé, S. (2009). Why is prosody in speech-language pathology so difficult? International Journal of Speech-Language Pathology, 11, 258-271. 
Peppé, S. J. E., Cleland, J., Gibbon, F. E., O’Hare, A. E., \& Martínez-Castilla, P. (2011). Expressive prosody in children with autism spectrum conditions. Journal of Neurolinguistics, 24, 41-53.

Peppé, S., McCann, J., Gibbon, F., O'Hare, A., \& Rutherford, M. (2007). Receptive and expressive prosodic ability in children with high-functioning autism. Journal of Speech, Language \& Hearing Research, 50, 1015-1028.

Peppé, S., McCann, J., Gibbon, F., O’Hare, A., \& Rutherford, M. (2006). Assessing prosodic and pragmatic ability in children with high-functioning autism. Journal of Pragmatics, 38, 1776-1791.

Pijnacker, J., Geurts, B., Van Lambalgen, M., Kan, C. C., Buitelaar, J. K., \& Hagoort, P. (2009). Defeasible reasoning in high-functioning adults with autism: Evidence for impaired exception-handling. Neuropsychologia, 47, 644-651.

Provonost, W., Wakstein, M., \& Wakstein, D. (1966). A longitudinal study of speech behaviors and language comprehension in fourteen children diagnosed as atypical or autistic. Exceptional Children, 33, 19-26.

Russo, N., Flanagan, T., Iarocci, G., Berringer, D., Zelazo, P.D., \& Burack, J.A. (2007). Deconstructing executive deficits among persons with autism: Implications for cognitive neuroscience. Brain and Cognition 65, 77-86.

Russo, N. M., Skoe, E., Trommer, B., Nicol, T., Zecker, S., Bradlow, A., et al. (2008). Deficient brainstem encoding of pitch in children with autism spectrum disorders. Clinical Neurophysiology, 119, 1720-31. 
Rutherford, M. D., Baron-Cohen, S., \& Wheelwright, S. (2002). Reading the mind in the voice: A study with normal adults and adults with asperger syndrome and high functioning autism. Journal of Autism \& Developmental Disorders, 32, 189-194.

Rutter, M., Bailey, A., Berument, S. K., Lord, C., \& Pickles, A. (2003). Social communication questionnaire (SCQ). Los Angeles: Western Psychological Services.

Rutter, M., Le Couteur, A., \& Lord, C. (2003). Autism diagnostic interview-revised. Los Angeles: Western Psychological Services.

Selkirk, E. O. (1986). On derived domains in sentence phonology. Phonology, 3, 371405.

Semel, E., Wiig, E. H., \& Secord, W. A. (2003). Clinical Evaluation of Language Fundamentals (CELF-4). San Antonio, TX: The Psychological Corporation.

Shattuck-Hufnagel, S. \& Turk, A. (1996). A prosody tutorial for investigators of auditory sentence processing. Journal of Psycholinguistic Research, 25, 193-247.

Shriberg, L. D., Paul, R., Black, L. M., \& van Santen, J. P. H. (2011). The hypothesis of apraxia of speech in children with autism spectrum disorder. Journal of Autism and Developmental Disorders, 41, 405-426.

Snedeker, J. \& Trueswell, J. (2003). Using Prosody to Avoid Ambiguity: Effects of Speaker Awareness and Referential Context. Journal of Memory and Language, 48, 103-130.

Snedeker, J. \& Trueswell, J. (2004). The developing constraints on parsing decisions: The role of lexical-biases and referential scenes in child and adult sentence processing. Cognitive Psychology, 49, 238-299. 
Snedeker, J., \& Yuan, S. (2008). Effects of prosodic and lexical constraints on parsing in young children (and adults). Journal of Memory and Language, 58, 574-608.

Speer, S. R. \& Ito, K. (2009). Prosody in first language acquisition - Acquiring intonation as a tool to organize information in conversation. Language and Linguistics Compass, $3,90-110$.

Tager-Flusberg, H., Paul, R., \& Lord, C. (2005). Language and communication in autism. In F. R. Volkmar, R. Paul, A. Klin \& D. J. Cohen (Eds.), Handbook of autism and pervasive developmental disorders: Diagnosis, development, neurobiology, and behavior (Third ed., pp. 335-364). Hoboken, New Jersey: John Wiley \& Sons, Inc.

Tanenhaus, M. K., Spivey-Knowlton, M. J., Eberhard, K. M., \& Sedivy, J. C. (1995). Integration of visual and linguistic information in spoken language comprehension. Science, 268, 1632-1634.

Thothathiri, M., \& Snedeker, J. (2008a). Syntactic priming during language comprehension in three- and four-year-old children. Journal of Memory and Language, 58, 188-213.

Thothathiri, M., \& Snedeker, J. (2008b). Give and take: Syntactic priming during spoken language comprehension. Cognition, 108, 51-68.

Trueswell, J. C., Sekerina, I., Hill, N. M., \& Logrip, M. L. (1999). The kindergarten-path effect: Studying on-line sentence processing in young children. Cognition, 73, 89-134.

Verte, S., Guerts, H., Roeyers, H., Ooosterlaan, J., \& Sergeant, J. (2006). Executive functioning in children with an autism spectrum disorder: Can we differentiate within the spectrum? Journal of Autism and Developmental Disorders, 36, 351-372. 
Vogel, I, \& Raimy, E. (2002). The acquisition of compound vs. phrasal stress: the role of prosodic constituents. Journal of Child Language, 29, 225-250.

Wagner, M., \& Watson, D. (2010). Experimental and theoretical advances in prosody: A review. Introduction to Special Issue of Language and Cognitive Processes, 25, 905945.

Wechsler, D. (1999). Wechsler abbreviated scale of intelligence. San Antonio: Pearson. Weighall, A. (2008). The kindergarten path effect revisited: Children's use of context when processing structural ambiguities. Journal of Experimental Child Psychology, 99, 75-95.

Young, E. C., Diehl, J. J., Morris, D., Hyman, S. L., \& Bennetto, L. (2005). The use of two language tests to identify pragmatic language problems in children with autism spectrum disorders. Language, Speech, and Hearing Services in Schools, 36, 62-72. 